\title{
Health Care Costs and the Arc of Innovation
}

Neel U. Sukhatme

Georgetown University Law Center, nus6@georgetown.edu

Maxwell Gregg Bloche

Georgetown University Law Center, bloche@law.georgetown.edu

This paper can be downloaded free of charge from:

https://scholarship.law.georgetown.edu/facpub/2153

https://ssrn.com/abstract=3514238

Minnesota Law Review, Vol. 104, Issue 2, 955.

This open-access article is brought to you by the Georgetown Law Library. Posted with permission of the author. Follow this and additional works at: https://scholarship.law.georgetown.edu/facpub

Part of the Health Law and Policy Commons, Intellectual Property Law Commons, and the Law and Society Commons 


\section{Article}

\section{Health Care Costs and the Arc of Innovation}

\section{Neel U. Sukhatme ${ }^{\dagger}$ and M. Gregg Bloche ${ }^{\dagger \dagger}$}

Introduction 957

I. Medical Cost Control: Fifty Years of Failure 964

A. "Don't Pull the Plug on Grandma": The Psychology of Rescue and the Ethics of Medicine ......................... 967

1. Rescue and Clinical Spending .............................. 967

2. Clinical Ethics .................................................... 968

3. Research Ethics and Statistical v. Therapeutic Significance ........................................................... 970

4. The Steep Price of Rescue ................................... 971

5. A Doctors' Plot? ......................................................... 978

$\dagger$ Associate Professor (J.D., Ph.D. Economics), Georgetown University Law Center; Affiliated Faculty Member, Georgetown University McCourt School of Public Policy. Copyright (C 2019 by Neel U. Sukhatme.

†† Professor of Law (J.D., M.D.), Georgetown University Law Center; CoDirector, Georgetown-Johns Hopkins Joint Program in Law and Public Health. Copyright (c) 2019 by M. Gregg Bloche.

One of our names must appear first, but neither of us is "first author." This Article is a joint product, to which we contributed equally. It would not have been possible without the cross-fertilization made possible by our mix of backgrounds in health and intellectual property law, economics, and medicine. We tossed a coin to determine the author sequence. We especially thank our collaborator, John Marshall, M.D., with whom we are presently developing an empirical proof of concept of the ideas discussed here. We also thank participants and attendees at the 2017 Works-in-Progress IP Colloquium at Boston University; the 2017 IP Scholars Conference at Cardozo Law; the Washington University School of Law Faculty Workshop; the Georgetown Law Faculty Research Workshop, the Stanford Law School Bio Law Lapalooza, and the University of Heidelberg Global Health Lecture series; as well as Nicholas Bagley, Scott Baker, Bill Buzbee, Anupam Chander, Sherry Glied, Brian Galle, Paul Gugliuzza, Daniel Halperin, David Hyman, Scott Kostyshak, Son Le, Adam Levitin, Glynn Lunney, Rachel Sachs, Steve Salop, Johanna Spellman, Sandra Swain, Josh Teitelbaum, Timothy Westmoreland, and Marc Zubick. Special thanks to Leo Acklin, Yinan Lin, Flora Feng, and Thanh Nguyen for excellent research assistance. Any errors are the authors' own. 
B. Law and the Neglect of Cost ....................................... 978

1. Medical Tort Law ................................................ 979

2. Coverage Disputes and Independent Review ...... 980

3. FDA Criteria for New Drugs and Medical Devices ............................................................. 982

4. Patent Law and Drug Companies' Reach for Mediocrity .......................................................... 983

5. The ACA's Prohibitions Against "Rationing" and the Use of "Quality-Adjusted Life Years" ..... 987

6. Medicare's Separation of Decisions about Coverage and Payment

C. Stakeholders, Expectations, and Levers of

Influence 992

D. A Lightning-Round Review of Failed Cost-Control

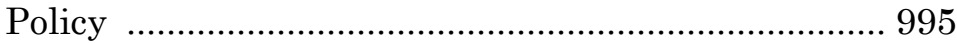

1. Health Planning ................................................. 996

2. Hospital Rate Regulation ................................... 998

3. The Market Responds: Managed Care ................ 999

4. Top-Down Caps on Medical Spending ............... 1005

II. Beyond Futility: An Emergent Strategy ...................... 1007

A. Quantum Leaps v. "Half-Way Technologies" ........... 1007

B. Scaling Economic Reward to Therapeutic Impact .. 1011

1. Toward Dynamic Value-Based Payment ........... 1012

2. Toward Dynamic Patent Protection ................... 1014

III. Bending the Arc of Innovation: Value-Based Payment and Value-Based Patents .................................................. 1017

A. Blueprint for Valuing New Clinical Methods .......... 1017

1. Criteria for a Measure of Clinical Value ........... 1019

2. A Model from Oncology ...................................... 1019

3. Expanding the Evidence Base: Electronic Medical Records and Machine Learning ........... 1022

4. Leveraging Legal Presumptions to Encourage Comparative-Effectiveness Research ............... 1025

B. Value-Based Payment ............................................ 1026

C. Value-Based Patents ............................................... 1030

1. A Dynamic, Value-Based Patent Term ............. 1030

2. Scientific and Competitive Uncertainty ............ 1032

3. The Hatch-Waxman Framework ....................... 1034

4. FDA-Conferred Market Exclusivity ................... 1036

5. America's International-Trade Obligations ....... 1037

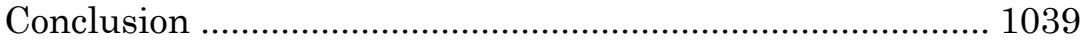




\section{INTRODUCTION}

Medical spending is the fiscal analogue of global warming. Anger over rising insurance premiums, drug prices, and bills from doctors and hospitals infuses our politics. Federal outlays on health care are projected to soar, from $28 \%$ to $40 \%$ of federal spending by $2047,{ }^{1}$ pushing public borrowing to levels that portend fiscal crisis. ${ }^{2}$ Within ten years, national debt is projected to approach or exceed $100 \%$ of gross domestic product (GDP), ${ }^{3}$ a marker associated in other countries with investor panic, spiking interest rates, and more general economic meltdown. ${ }^{4}$

Fear of uncontrolled medical costs has fueled resistance to the Affordable Care Act (ACA), ${ }^{5}$ stymied Medicaid expansion in some states,${ }^{6}$ and discouraged employers from offering medical

1. Jessica Banthin, Health Care Spending Today and in the Future: Impacts on Federal Deficits and Debt, ConG. BUDGET OFF. (July 18, 2017), https://www.cbo.gov/system/files/115th-congress-2017-2018/presentation/ 52913-presentation.pdf [https://perma.cc/KP7K-LL9A] (detailing percentages of federal spending exclusive of interest payment on the national debt).

2. Michael J. Boskin et al., A Debt Crisis Is on the Horizon, WAsH. PosT (Mar. 27, 2018), https://www.washingtonpost.com/opinions/the-debt-crisis-is -on-our-doorstep/2018/03/27/fd28318c-27d3-11e8-bc72-077aa4dab9ef_story .html?arc404=true [https://perma.cc/XJ6Y-WKYR].

3. Cong. Budget OfFice, The Budget And Econ. Outlook: 2018 to 2028, 86 (2018), https://www.cbo.gov/system/files/2019-04/53651-outlook-2.pdf [https://perma.cc/33ZU-MJ3S]. We use "Debt Held by the Public" as our metric of national debt; it includes all federal debt held by people or firms, state or local governments, Federal Reserve Banks, and foreign entities.

4. Absent rising medical spending, America's debt would stabilize as a fraction of GDP, climbing slowly from $77 \%$ in 2018 to $90 \%$ in 2028 , then slipping to $87 \%$ in 2040, according to Congressional Budget Office projections. But if current health spending trends continue, public debt will soar to $125 \%$ of GDP by 2040. American Health Care: Health Spending and the Federal Budget, CoMMITTEE FOR A RESPONSIBLE FED. BUDGET (May 14, 2018), https://www.crfb.org/ papers/american-health-care-health-spending-and-federal-budget [https:// perma.cc/CBT7-YM2T].

5. Paul R. Gordon et al., Opposition to Obamacare: A Closer Look, 92 ACAD. MED. 1241 (2017).

6. See Robert Pear \& Michael Cooper, Reluctance in Some States Over Medicaid Expansion, N.Y. TIMES (June 29, 2012), https://www.nytimes.com/ 2012/06/30/us/politics/some-states-reluctant-over-medicaid-expansion.html [https://perma.cc/E5SE-TRXX]; Tami Luhby, States Forgo Billions by Opting Out of Medicaid Expansion, CNN (July 1, 2013), https://money.cnn.com/2013/ 07/01/news/economy/medicaid-expansion-states/index.html [https://perma.cc/ 7PTG-A9WH]. 
coverage. ${ }^{7}$ Meanwhile, rising premiums ${ }^{8}$ and out-of-pocket $\operatorname{costs}^{9}$ are stressing families and fomenting anger at health plans, doctors and hospitals, and elected officials. ${ }^{10}$

For more than seventy years, since the spread of employment-based medical insurance during World War II, U.S. medical spending has risen more rapidly than our country's GDP. ${ }^{11}$ There have been brief breaks from this pattern, coinciding with

7. See Laura Lorenzetti, This Workplace Perk Is Slowly Going Extinct, FORTUNE (Mar. 30, 2016), http://fortune.com/2016/03/30/employer-paid-health -insurance-is-dying-off/ [https://perma.cc/L7DG-LD7B]; Robert King, Study: Fewer Employers Offering Health Insurance, WASH. EXAMINER (Feb. 22, 2017), https://www.washingtonexaminer.com/study-fewer-employers-offering-health -insurance [https://perma.cc/3ERA-YJ83].

8. Premiums for benchmark "Silver" plans on the ACA's Insurance Exchanges increased by an average of $20 \%$ in 2016. John Holahan et al., What Explains the 21 Percent Increase in 2017 Marketplace Premiums, and Why Do Increases Vary Across the Country?, URB. INST. (Jan. 2017), https://www.urban .org/sites/default/files/publication/87021/2001052-what-explains-the-21 -percent-increase-in-2017-marketplace-premiums-and-why-do-increases-vary -across-the-country_1.pdf [https://perma.cc/39YP-42BH]. Individual-market premiums have more recently risen more slowly, albeit with wide local variations. Rabah Kamal et al., 2019 Premium Changes on ACA Exchanges, KAISER FAMILY FOUND. (Oct. 11, 2018), https://www.kff.org/health-costs/issue-brief/ tracking-2019-premium-changes-on-aca-exchanges/ [https://perma.cc/S7ZC

-W7G3]. Average annual price increases for employment-based coverage have remained in the single digits for the last several years, but they've typically outpaced the general rate of inflation by a few to several percentage points. Gary Claxton et al., Health Benefits in 2018: Modest Growth in Premiums, Higher Worker Contributions at Firms with More Low-Wage Workers, 37 HEALTH AFF. 1892 (2018); 2017 Employer Health Benefits Survey, KAISER FAM. FOUND. (Sept. 19, 2017), https://www.kff.org/report-section/ehbs-2017-summary-of-findings/ [https://perma.cc/5V89-LNAD].

9. Gary Claxton et al., Increases in Cost-Sharing Payments Continue to Outpace Wage Growth, KAISER FAMILY FOUND. (June 15, 2018), https://www .healthsystemtracker.org/brief/increases-in-cost-sharing-payments-have-far -outpaced-wage-growth/ [https://perma.cc/FA2H-GE7Q].

10. Consumer Attitudes on Health Care Costs: Insights from Focus Groups in Four Cities, Anger and Confusion as Rising Premiums and High Deductibles Claim a Bigger Share of Household Budgets, ROBERT WOOD JOHNSON FOUND. (Jan. 2013), https://www.rwjf.org/content/dam/farm/reports/issue_briefs/2013/ rwjf403428 [https://perma.cc/D938-DYYQ]; Helaine Olen, Even the Insured Often Can't Afford Their Medical Bills, ATLANTIC (June 18, 2017), https://www .theatlantic.com/business/archive/2017/06/medical-bills/530679/ [https://perma .cc7V4V-6KHT].

11. U.S. National Health Expenditure as Percent of GDP from 1960 to 2019, STATISTA, https://www.statista.com/statistics/184968/us-health-expenditure-as -percent-of-gdp-since-1960/ [https://perma.cc/AB8B-C5FL]. 
steep recessions ${ }^{12}$ and one-off changes in health care payment practice. ${ }^{13}$ But the long-term trend line has been steadily upward, toward nearly $18 \%$ of GDP by $2017 .{ }^{14}$ After several years of deceptive stability in the wake of the Great Recession, ${ }^{15}$ health spending rose by 3.7 percentage points more than general inflation $^{16}$ in 2014 , then by $5.8 \%$ more in $2015 .{ }^{17}$ For 2016 to 2025 , the federal government projects further increases averaging $5.6 \%$ per year (not adjusted for inflation) - 1.2 percentage points beyond annual GDP growth-pushing health spending to one fifth of GDP by the end of this period. ${ }^{18}$ Longer-term projections,

12. Medical spending stayed flat, as a portion of GDP, for several years during and after the deep recessions of 1980-1981 and 2008-2009. Louise Sheiner, Perspectives on Health Spending Growth, FED. RESERve BoARD. OF GoverNORS (Apr. 11, 2014), https://www.brookings.edu/wp-content/uploads/2014/03/ 411_Health_Care_Spending_Deck_ALL-PANELS.pdf [https://perma.cc/P6LK -V32G].

13. See Stuart Guterman \& Allen Dobson, Impact of the Medicare Prospective Payment System for Hospitals, 7 HEALTH CARE FIN. REV. 3 (1986) (describing how Medicare's 1983 shift from fee-for-service payment for hospital care to payment based on diagnostic category led to shorter hospitalizations and other spending reductions for both Medicare and non-Medicare patients); AARON CATLIN \& CATHY COWAN, History OF HEALTH SPENDING IN THE UNITED STATES, 1960-2013 (2015), https://www.cms.gov/Research-Statistics-Data-and -Systems/Statistics-Trends-and-Reports/NationalHealthExpendData/ Downloads/HistoricalNHEPaper.pdf [https://perma.cc/TK8W-PQJK]

(documenting another plateau in health spending as a proportion of GDP in the mid-1990s, associated with many employers' shift from fee-for-service to more frugal "managed care" plans for their employees).

14. Andrea M. Sisko et al., National Health Expenditure Projections, 201827: Economic and Demographic Trends Drive Spending and Enrollment Growth, 38 HEALTH AFF. 491 (2019) (reporting that total U.S. private and public health care spending reached $17.9 \%$ of GDP in 2017 and projecting a further rise to $19.4 \%$ by 2027 , based on CMS data and assumptions).

15. See CATLIN \& CoWAN, supra note 13 (documenting health spending that stayed approximately flat as a percentage of GDP during and immediately after the "Great Recession").

16. Historical Inflation Rates: 1914-2019, U.S. INFLATION CALCULATOR, http://www.usinflationcalculator.com/inflation/historical-inflation-rates/ [https://perma.cc/47PH-VFS7].

17. NHE Factsheet, CENTERS FOR MEDICARE \& MEDiCAID SERVICES (2017), https://www.cms.gov/research-statistics-data-and-systems/statistics-trends -and-reports/nationalhealthexpenddata/nhe-fact-sheet.html [https://perma.cc/ HLE6-ZZEN]. We subtracted the 2014 and 2015 general inflation rates from each year's health spending increase to obtain the percentages in the text above.

18. Id. CMS projects that national health spending will be $19.9 \%$ of GDP in 2025. CMS issues annual ten-year projections that vary slightly as assumptions 
typically less reliable, call for medical spending to surpass $30 \%$ of GDP by mid-century. ${ }^{19}$

Medical costs pose a mounting threat to our country's fiscal stability, crowd out other pressing public needs, and are a growing burden on businesses and families. ${ }^{20}$ Employers experience this burden in the form of the rising proportions of total operating expenses they must budget to cover employees' health care costs, either directly ${ }^{21}$ or through purchase of insurance. Individuals feel it in the form of rising premiums, copayments, and deductibles that reduce their standards of living and ability to invest in their futures.

Ever-increasing medical costs, moreover, stand in the way of efforts to expand access to care. Soaring premiums for coverage sold on ACA Insurance Exchanges ${ }^{22}$ soured millions on the ACA's access-expanding potential. ${ }^{23}$ Insurers' efforts to constrain premiums by narrowing their provider networks ${ }^{24}$ and raising subscribers' cost-sharing burdens ${ }^{25}$ further diminished

evolve and data are updated; in February 2019, the agency projected that health spending would rise to $19.4 \%$ of GDP by 2027. Sisko et al., supra note 14 .

19. Stephen Heffler et al., The Long-Term Projection Assumptions for Medicare and Aggregate National Health Expenditures, CENTERS For MEDICARE \& MEDICAID SERVICES. (Nov. 27, 2012), https://www.cms.gov/Research-Statistics -Data-and-Systems/Statistics-Trends-and-Reports/ReportsTrustFunds/ Downloads/ProjectionMethodology2012.pdf [https://perma.cc/47MD-U29M].

20. Rising Medicare costs are the main factor in long-term projections of mounting federal budget deficits. The 2018 Long-Term Budget Outlook, ConG. BUDGET OFF. (June 2018), https://www.cbo.gov/system/files?file=2018-06/53919 -2018ltbo.pdf [https://perma.ccJ9QJ-Y92J] The federal government's failure to gain long-term control of Medicare costs was the main reason Standard and Poor's gave for its 2011 downgrading of U.S. sovereign debt from AAA to AA+, a downgrade that still stands. Charles Riley, S\&P Downgrades U.S. Credit Rating, CNN (Aug. 6, 2011), https://money.cnn.com/2011/08/05/news/economy/ downgrade_rumors/index.htm [https://perma.cc/5L9N-F9P7].

21. Larger employers tend to "self-insure"-an industry euphemism for setting aside funds to cover employees' medical costs without purchasing insurance.

22. See supra note 8 .

23. Vladimir Kogan \& Thomas J. Wood, Obamacare Implementation and the 2016 Election (Feb. 6, 2019), http://dx.doi.org/10.2139/ssrn.3075406 [https:// perma.cc/H8HQ-GHZF].

24. Austin Frakt, Savings? Yes. But Narrow Health Networks Also Show Troubling Signs, N.Y. TIMES (Oct. 16, 2016), https:/www.nytimes.com/2016/ 10/18/upshot/savings-yes-but-narrow-health-networks-also-show-troubling -signs.html?_r=0 [https://perma.cc/434D-EBVG].

25. Health Policy Brief: High-Deductible Health Plans, Health AFF. (Feb. 
the ACA as a value proposition in the eyes of many, ${ }^{26}$ perhaps playing a role in Donald Trump's electoral victory on a platform that included the law's repeal. ${ }^{27}$ And apprehension over uncontrolled costs has discouraged states from expanding Medicaid28 and fed resistance to funding the ACA's cost-sharing reductions for lower-income health insurance purchasers.

Many factors influence health spending, including coverage expansion, the balance of bargaining power between payers and providers, and the aging of America's population. But the main driving force behind rising spending, long-term, is technological advance, fueled by health insurance's promise of rich reward. ${ }^{29}$ If this advance delivered value commensurate with its opportunity costs, we could celebrate it as unalloyed accomplishment; it's the market distortion induced by insurers' coverage of health care prices at the point of purchase that creates large potential for waste.

Here, the health law and policy literature mostly misses a critical point. This literature is replete with references to "moral hazard"-health insurance's tendency to induce wasteful spending by reducing the prices patients pay out-of-pocket for care. But the more important, long-term effect of medical insurance on health care costs is dynamic: the expected availability of coverage for future advances-even those that yield only small incremental benefits-spurs technological innovation with little regard for therapeutic value and minimal concern about price. ${ }^{30}$

4, 2016), http://healthaffairs.org/healthpolicybriefs/brief_pdfs/ healthpolicybrief_152.pdf [https://perma.cc/PT58-R6LV].

26. Sarah Kliff, Why Obamacare Enrollees Voted for Trump, Vox (Dec. 13, 2016), https://www.vox.com/science-and-health/2016/12/13/13848794/kentucky -obamacare-trump [https://perma.cc/K6PH-XE9U].

27. Id.; Kogan \& Wood, supra note 23.

28. Kimberly Leonard, Opposing Medicaid Expansion, U.S. NEWS (Dec. 4, 2015), https:/www.usnews.com/news/the-report/articles/2015/12/04/opposing -medicaid-expansion [https://perma.cc/RQ88-DGSF].

29. Henry AARon, Serious AND UnStABle CONDITION 24-27 (1991).

30. See id. (suggesting various tax reforms and changes to Medicare to accomplish this); see also Nicholas BAGLEY ET AL., THE HAMILTON Project, DisCUSSION PAPER 2015-09, CORRECTING Signal, FOR INNOVATION IN HEALTH CARE, (Oct. 2015), https://www.hamiltonproject.org/assets/files/correcting_ signals_for_innovation_in_health_care_bagley.pdf [https://perma.cc/JU8J -9KTD] ("Addressing the incentives for technology development, and not just its diffusion once invented, is critical [for controlling health care costs.]"). 
Since out-of-control clinical spending was first recognized as a problem in the mid-1960s, federal and state policymakers have tried to gain control of it via a wide array of regulatory and market-oriented strategies. ${ }^{31}$ These efforts have uniformly failed. In this Article, we explain why. Our explanation breaks with traditional liberal and conservative accounts of this spending as the product of poorly-regulated industry actors, overly-interventionist government, or some mix of both. Rather, we argue, America's escalating failure to contain it is the product of an intractable tangle of human psychology, cultural mores, clinical ethics, and stakeholder expectations.

Large legal and political obstacles to medical cost-containment both reflect and reinforce this phenomenon. Law, psychology, culture, and industry actors' embedded expectations ensure fulsome rewards for even tiny clinical advances. And once a test or treatment comes onto the market, this tangle of influences makes it nearly impossible for our health care system to say no if there's a plausible case for some small therapeutic benefit.

The legal and regulatory schemes that govern public and private health care payment and provision consign cost-benefit tradeoffs to the down-low. Health policy's most dreaded word, "rationing," is an equal-opportunity cudgel, wielded by Democrats and Republicans, patients and providers, and drug and device makers to defeat such tradeoffs. Criticizing law's obstacles to setting limits is easy and often done, from diverse ideological perspectives. But doing so begs the question of how to overcome the psychological, cultural, and institutional influences that hold these obstacles in place.

Over the past fifty years, we contend below, no regulatory or market-oriented approach to medical costs has taken serious account of this Gordian knot of influences. Our central proposition in this Article is that the medical cost crisis that threatens America's fiscal stability, consumer well-being, and competitiveness cannot be managed unless law and politics take on this challenge.

In Part I, we explain how this Gordian tangle and the legal regimes that reinforce it have stymied cost-control efforts. We

31. Stuart Altman \& Robert Mechanic, Health Care Cost Control: Where Do We Go from Here?, HEALTH AFF. (July 13, 2018), https://www.healthaffairs .org/do/10.1377/hblog20180705.24704/full/. 
then review the record of failure, from the "health systems planning" movement of the late 1960s through "managed care" to recent efforts to cap health care entitlement programs and to make patients more price-conscious by boosting co-payments and deductibles. Though these strategies have sharply different ideological roots, they've failed for the same core reasons.

In Part II, we urge a legal and regulatory strategy that finesses the forces behind this failure. We play the long game, by minimizing disruption of vested expectations and averting arrangements that push patients and families into agonizing choices between catastrophic expense and forgoing potentially life-saving care. Instead, we aim to dramatically shift the trajectory of innovation, away from the high-cost, low-value advances that play an outsized role in raising spending.

To this end, we propose a novel reward system for innovation tied to therapeutic value. We urge that prices for new clinical measures be set, then continually adjusted, based on emerging evidence of efficacy. And we propose a fundamental change in the law's treatment of intellectual property-a shift to variable patent terms (and other forms of market exclusivity) for medical technologies, tied to evolving evidence of clinical value. This sharp break with one-size-fits-all market exclusivity outside the health sphere is urgently needed, we contend, because of the medical marketplace's unique, enormous dysfunction-its inability to translate real value into economic reward.

Finally, in Part III, we outline legal and regulatory changes needed to give effect to our vision for changing the trajectory of innovation. We first propose a scheme for valuing the efficacy of emerging diagnostic and therapeutic measures-a scheme that incorporates patients' diverse concerns and draws upon large advances in information technology's capacity to track and learn from real-world clinical outcomes. Next, we urge changes to the law governing health care payment so as to shift its basis from the cost of emerging services to their efficacy. Then, we offer a blueprint for a transformed regime of intellectual property protection in the health sphere, based on value. After sketching the outlines of an ideal regime, we identify practical reforms, building on the Hatch-Waxman Act and other current law, that would move health care intellectual property law in this direction. 
The approach we urge here is feasible because it finesses stakeholders' settled expectations. It changes industry actors' incentives for research and development decisions they haven't yet made, while leaving incentive schemes for already-made commitments in place. It thus dramatically dials down development of the high-cost, low-benefit tests and treatments that are the main drivers of soaring spending. Our approach thereby achieves cost containment without putting payers, politicians, and physicians in the untenable position of often needing to say "no" to potentially life-prolonging measures.

\section{MEDICAL COST-CONTROL: FIFTY YEARS OF FAILURE}

Some contend that rising medical costs aren't a problem. Between 1940 and 1990, economist Sherry Glied notes, declining spending on food almost exactly offset soaring spending on health care. ${ }^{32}$ In 1940, Americans devoted nearly $30 \%$ of household income to food and only a few percent to medical care. ${ }^{33}$ Fifty years later, the fraction of income spent on food had fallen by half; health spending, meanwhile, had risen to fill this gap. ${ }^{34}$ The larger point here is that household spending across different economic sectors fluctuates over time. Rapid growth in one sector isn't necessarily an indicator of trouble; to the contrary, it's often seen as a sign of vibrancy. By 2010, for example, information and communications technology production had reached nearly $5 \%$ of U.S. GDP, 35 up from less than $1 \%$ in 1980.36

Americans embrace this as progress-a boost for both productivity and people's satisfaction. And society defers to market choice as the measure of value for $\$ 1,200$ iPhones, $\$ 300$ ripped jeans, and most other products and services. ${ }^{37}$ Health

32. Sherry Glied, Chronic Condition: Why Health Reform Fails 102-03 (1997). We were, of course, hardly eating less by 1990 than we were in 1940, as the American obesity epidemic (which began in the 1980s) underscores. Rather, as Glied points out, the relative production costs of food fell.

33. Id.

34. $I d$.

35. NAT'L RES. COUNCIL, CONTINUING INNOVATION IN INFORMATION TECH. (2012), https://www.nap.edu/read/13427/chapter/2 [https://perma.cc/9YRA $-57 \mathrm{JG}]$.

36. Ian Hathaway, How Big Is the Tech Sector? (May 31, 2017), http://www .ianhathaway.org/blog/2017/5/31/how-big-is-the-tech-sector [https://perma.cc/ 9G5G-TNSV].

37. True, product reviewers, cultural critics, and others question our consumer choices, but we don't typically marshal the law to enforce these doubts. 
care, though, is different, since people for the most part don't pay for it with their own money: $75 \%$ of the $\$ 3.5$ trillion the nation spent on medical care in 2017 was covered by insurers. ${ }^{38}$ Insurance, health economists hold, creates "moral hazard" by enabling patients to purchase care for a fraction of its actual cost. ${ }^{39}$ Waste ensues, this story says, when patients purchase services that they value at less than actual cost but more highly than their out-of-pocket payments. There are deep flaws in this standard story, ${ }^{40}$ but its core message is spot-on: by slashing consumers' out-of-pocket prices, health insurance fuels the provision of medical care at higher-than-optimal levels as physicians evolve clinical standards that incorporate this distortion. More importantly over the long-term, insurance overstimulates investment in the development of new clinical technologies with low future benefits, relative to their cost.

The result is rising waste ${ }^{41}$ as health spending soars. Consumer welfare suffers as medical insurance siphons resources, via premium payments, from higher-value uses (beyond the health sector) to low-benefit clinical services. Likewise, individuals and businesses are less able to invest for the future-medical spending crowds out commitments of resources to education, research and development, and capital expenditures. Governments responsible for public insurance programs face an especially tight squeeze-between these programs' rising costs and voters' resistance to higher taxes. The result is the rerouting of

38. Sisko et al., supra note 14, at 492 Exhibit 1 . Individuals pay for this, of course, in the form of taxes, insurance premiums, and (in the case of employees who obtain coverage through their workplaces) reduced wages; the point here is that patients aren't hit with these costs when care is provided.

39. E.g., Martin S. Feldstein, Hospital Cost Inflation: A Study of Nonprofit Price Dynamics, 61 AM. ECON. REV. 853 (1971).

40. For a discussion (by one of us) of some of the moral-hazard story's most worrisome defects, see M. Gregg Bloche, The Invention of Health Law, $91 \mathrm{CAL}$ L. REV. 247, 260-66 (2003) (arguing that health economists invoke moral hazard in a way that overstates "waste" by failing to account for the benefits (both tangible and psychological) of insurance as a safety net when health crises strike and that hides other normative questions about what should and shouldn't count as waste).

41. We understand "waste" here in the economic sense, as an expenditure's excess of cost (including opportunity cost) over benefit. 
funds from other public programs to medical care, shortchanging myriad priorities, from education ${ }^{42}$ to national defense..$^{43}$

Moreover, some contend that America's disproportionately high health spending, relative to other industrialized nations, undermines the global competitiveness of U.S. business by elevating labor costs. ${ }^{44}$ This is a controversial proposition-others claim this effect is mythic because employers restrain wages to cover their workers' medical costs, ensuring that total employee compensation is unaffected by health spending. ${ }^{45}$ But even if wages adjust without friction to fully account for medical costs, reduced consumer spending and public and private investment in education, research and development, and other productivityenhancing endeavors likely translates into diminished capacity to compete in global markets.

Soaring health care costs thus pose a huge challenge to American fiscal stability and personal well-being. Why has the U.S. failed so utterly over the past half-century to meet this challenge? At the heart of the problem, we contend here, is the psychological difficulty of withholding care that might save lives, ameliorate misery, or reduce disability. Doing so in the open inspires outrage - from patients, family and friends, and society at large. ${ }^{46}$ Cultural mores, clinical ethics, and law reflect and reinforce this psychology. And stakeholders in the medical economy benefit from and entrench it as they pitch their products and press their interests through politics and law. This tangle of personal and social expectations, ethical and legal obligation, and stakeholder influence stymies efforts to say "no" to tests and treatments thought to offer even small benefits, regardless of cost. The history of medical cost-containment policy is a record of this recurring failure.

42. Douglas Webber, Higher Ed, Lower Spending, EDUC. NEXT (May 2, 2018), https://www.educationnext.org/higher-ed-lower-spending-as-states-cut -back-where-has-money-gone/ [https://perma.cc/8MLW-QJ2R].

43. Avik Roy, A Real Domestic Threat: How Health-Care Spending Strains the U.S. Military, ATLANTIC (Mar. 12, 2012), https://www.theatlantic.com/ business/archive/2012/03/a-real-domestic-threat-how-health-care-spending -strains-the-us-military/254350/ [https://perma.cc/D94Y-T2TD].

44. E.g., Lester Thurow, Head to Head: The Coming ECONOMic Battle AMONG JAPAN, EUROPE, AND AMERICA (rev. ed. 1994).

45. GLIED, supra note 32, at 107-08.

46. M. Gregg Bloche, The Hippocratic MYTh 17-47 (2011). 


\section{A. "Don't Pull the Plug on Grandma": The Psychology of RESCUE AND THE ETHICs OF MEDICINE}

In the film, Saving Private Ryan, ${ }^{47}$ the larger ends of America in World War II dissolve as an army platoon takes senseless risks to search for a missing comrade-senseless, that is, if one disregards the combat deaths of his three brothers. That this family catastrophe justifies General George C. Marshall's order to his commanders to find Ryan and "get him the hell out of there" is the film's central trope. Men die as this quest unfolds. The campaign against the Nazis takes a back seat. Yet the soldiers' sacrifice seems ennobled by their mutual devotion. 48

More generally, we admire, even romanticize those who take great risks to save others, even when cold reason shows that these risks are disproportionate. ${ }^{49}$ And we marshal shared resources to rescue people in dire circumstances even when costbenefit calculus commands the conclusion that these resources would make a larger social difference if spent on other purposes. ${ }^{50}$

\section{Rescue and Clinical Spending}

We're hard-wired to come to the aid of people we know are in distress, to admire those who make sacrifices to do so, and to scorn those who refrain. ${ }^{51}$ A large literature documents our departure from the sensible ways of Homo Economicus as regards the distinctions we draw, through our actions, between identifiable and statistical lives-and between identified people's concerns and abstract purposes more generally.52 This departure drives our greater willingness to devote resources to rescue of identified individuals than to ex ante prevention of harm to them, even when the latter is much more cost-effective.

47. SAVING PRIVAte RYAN (Paramount Pictures 1998).

48. BLOCHE, supra note 46 , at 54 .

49. Id. at 55 .

50. Id. at $38,45-47$.

51. Francis T. McAndrew, New Evolutionary Perspectives on Altruism: Multilevel-Selection and Costly-Signaling Theories, 11 CURRENT DIRECTIONS PSYCH. SCI. 79, 79-80 (2002).

52. E.g., Milan Zafirovski, Rational Choice Requiem: The Decline of an Economic Paradigm and its Implications for Sociology, 45 AM. Soc'Y 432, 435 (2018). 
Health spending priorities express this preference. In the face of vast evidence that investment in public health and alleviation of poverty promote population-wide health much more cost-effectively than does rescue-oriented medical technology, ${ }^{53}$ the U.S. and the rest of the world spend disproportionately on the latter-disproportionately, that is, relative to health outcomes.

It's easy to say that we shouldn't do this. Academic literature in multiple disciplines is replete with appeals to this effect. But the non-cognitive responses that incline us this way are part of who we are, and democratic and market mechanisms of social decision-making inevitably reflect them. Candidates for political office don't run on promises to shut down surgical suites and intensive care units (ICUs) to free up funds for public parks or education. And medical insurers don't market plans that promise to better people's lives by withholding access to desperate measures so they can invest, instead, in gym memberships or college.

Physicians and hospitals deliver on these expectations. In emergencies, hospitals are legally obligated to do so even for patients who cannot pay: a 1986 statute conditions participation in Medicare on provision of emergency care to all. ${ }^{54}$ That this law singled out emergency, allowing hospitals to withhold less urgent services, underscores the political priority of rescue.

\section{Clinical Ethics}

Medical ethics, as well, reflect and reinforce the priority of rescue - and, more generally, the priority of individuals, no matter the social burden. The Hippocratic ideal of uncompromising loyalty to patients drives physicians to disregard social costs and to weigh only the expected therapeutic benefits and risks of tests and treatments, so long as insurance covers the bulk of the financial cost. 55 Were patients responsible for all or most of this cost, the Hippocratic ethic would command consideration of their economic burdens, as part of the duty to keep an eye single to

53. Dhruv Khullar \& Dave A. Chokshi, Health, Income, \& Poverty, HEALTH AFF. (Oct. 4, 2018), https://www.healthaffairs.org/do/10.1377/hpb20180817 .901935/full/ [https://perma.cc/TUG4-R5NF].

54. Emergency Medical Treatment and Active Labor Act, Pub. L. No. 99272, 100 Stat. 164 (1986) (codified at 42 U.S.C. § 1395dd (2012)).

55. BLOCHE, supra note 46 , at 46-47, 107-08. 
patient well-being. By analogy, lawyers, bound by a similar professional ethic of undivided loyalty to clients, are expected to adjust the services they provide to what their clients can afford. ${ }^{56}$ But when insurers pay all or most of the full freight, stinting on care that could prolong life, preserve capabilities, or provide comfort, it compromises patients' interests to benefit third-party bottom lines. Once a test or treatment becomes state-of-the-art, ethical practice bars withholding it based on cost.

The medical marketplace reinforces this ethic. More than fifty years ago, Kenneth Arrow explained the Hippocratic ideal of devotion to patient well-being as "part of the commodity the physician sells." 57 This ethical commitment, Arrow argued, enhances demand for health care by reassuring patients who are squeamish about their medical ignorance. Physician trustworthiness solves, or at least shrinks, the problem of information asymmetry between doctor and patient by signaling to prospective patients that physicians won't exploit this asymmetry for personal gain. ${ }^{58}$ Arrow focused on patients' worries about physician pursuit of financial gain, but the same argument applies to other breaches of loyalty, including stinting on care to save money for insurers.

Arrow's argument for information asymmetry as the source of patients' yearning for professional trustworthiness is, we think, both persuasive and incomplete. It leaves out the affective dimension of this human need-patients' craving for comfort and support through faith in their physicians. ${ }^{59}$

56. Michelle S. Jacobs, Legal Professionalism: Do Ethical Rules Require Zealous Representation for Poor People?, 8 ST. THOMAs L. REV. 97 (1995). Insurance for the cost of legal services is unusual, though commercial liability coverage often includes legal defense. Andrew Weiner \& Joseph Saka, The Basics of Commercial General Liability Policies, AM. BAR Assoc. (Aug. 27, 2013), https:// www.americanbar.org/groups/young_lawyers/publications/the_101_201_ practice_series/the_basics_of_commercial_general_liability_policies/ [https:// perma.cc/DY66-7ZZ2].

57. Kenneth J. Arrow, Uncertainty and the Welfare Economics of Medical Care, 53 AM. ECON. REv. 941, 965 (1963).

58. That physicians often honor this ethic in the breach, through increased use of services in which they have a financial interest, doesn't undermine Arrow's argument: less-than-complete adherence still provides a measure of reassurance. The import of trustworthiness in different economic endeavors arguably varies along a continuum, based on the magnitude of information asymmetries.

59. M. Gregg Bloche, The Market for Medical Ethics, 26 J. HEALTH POL. POL'Y \& L. 1099, 1108 (2001); $c f$. JAY KATZ, THE SILENT WORLD OF DOCTOR AND 
3. Research Ethics and Statistical v. Therapeutic Significance

The ethics of clinical research further reinforce the premise that only therapeutic risk and benefit matter. By longstanding precept, enshrined in federal human-subjects research regulations, clinical trials of tests and treatments can only be conducted when the alternatives to be studied are in "equipoise"that is, when there is "genuine uncertainty" on the investigator's part concerning these alternatives' comparative effectiveness. ${ }^{60}$ Cost is beside the point-a treatment that a researcher has reason to believe is slightly more effective than another cannot be compared to the other in a trial employing human subjects, even if the treatment believed to be better is much more expensive.

This ethical precept has the force of law. Federal regulations impose it for research conducted with federal funds. ${ }^{61}$ Institutional Review Boards generally mandate it even for privatelyfunded clinical trials. And when harm comes to a human subject enrolled in such a study, these regulations are likely to be treated as the standard of care for tort liability purposes. ${ }^{62} \mathrm{Hu}$ man-subjects research ethics thus further entrench the principle that doctors and hospitals have a duty to provide the most effective care, regardless of cost.

So does the standard clinical-research practice of elevating statistical over therapeutic significance. Researchers routinely design and evaluate clinical studies with a focus on the former at the expense of the latter. They choose outcome variables ${ }^{63}$ and

PATIENT 100-03 (1986) (discussing patients' psychological regression and resulting need to see their physicians as all-powerful in the way that young children view their parents).

60. Benjamin Freedman, Equipoise and the Ethics of Clinical Research, 317 NEW ENG. J. MED. 141 (1987).

61. 45 C.F.R. $§ 46.111$ (2012) (making no provision for cost reduction as a potential "benefit" meriting comparison of more versus less effective therapies).

62. Roger L. Jansson, Researcher Liability for Negligence in Human Subject Research: Informed Consent and Researcher Malpractice Actions, 78 WASH. L. REV. 229 (2003).

63. Designers of both prospective clinical trials and observational studies can choose from among a variety of metrics of effectiveness (known as study endpoints). Common metrics include rate of survival for a set time (often five years), progression-free survival (how long a patient lives with the disease without it getting worse), and time to progression (how long from diagnosis (or commencement of treatment) until the disease starts to get worse). NCI Dictionary of Cancer Terms, NAT'L CANCER INST., https://www.cancer.gov/publications/ dictionaries/cancer-terms?cdrid=44782 [https://perma.cc/DZ24-TRQ4]. 
courses of control versus experimental treatment with the aim of ensuring that the chance of a result's being real, not random, is tiny-typically less than 5\%. ${ }^{64}$ And so long as they achieve proof that one therapeutic approach yields a better outcome than another with a less than 5\% likelihood that this difference is a matter of chance, they treat the superiority of this approach as established-even if its therapeutic advantage is very small. Physicians then make it standard practice, ${ }^{65}$ and insurers come under pressure to cover it, ${ }^{6}$ even when tiny advantage comes at great expense.

\section{The Steep Price of Rescue}

The current surge in cancer treatments with sticker-shock prices illustrates this dynamic. A new generation of medications targets tumor blood flow, cellular metabolism, and immune responses to malignancy-and is pushing up prescription drug spending. ${ }^{67}$ Consider the case of colorectal cancer, the third-leading killer among malignancies (behind only breast and lung cancers).

Colorectal cancer afflicts 1.3 million Americans at any given time, with 140,000 new diagnoses and 50,000 deaths each year. ${ }^{68}$ Metastatic colorectal cancer (mCRC, also known as Stage IV)

64. Statistical significance refers to the probability that an experimental result (e.g., one treatment's superiority to another on a metric of performance) is not due to chance. Clinical researchers have long employed the "p-value" to measure this probability; as a matter of convention, researchers typically treat a result as "statistically significant" if its associated p-value is less than 0.05 $(\mathrm{p}<.05)$ - that is, if there is a less than $5 \%$ chance that the outcome was random.

65. See supra text accompanying notes 55-59 (discussing the medical profession's understanding that it is obligated to offer all treatments with net therapeutic benefit); see also infra text accompanying notes 106-17 (discussing legal pressures on physicians to offer such treatments).

66. See supra text accompanying notes 47-54 (discussing cultural, social, and thus market pressures on insurers to cover treatments with net therapeutic benefit); see also infra text accompanying notes 117-23 (discussing legal pressures to do so).

67. IMS Health, which tracks physician prescribing patterns, estimates that Americans paid nearly $\$ 310$ billion for prescription drugs in 2015 , up $8.5 \%$ from 2014. Medicines Use and Spending in the U.S., IMS INST. FOR HEALTHCARE INFORMATICS (2016), https://morningconsult.com/wp-content/ uploads/2016/04/IMS-Institute-US-Drug-Spending-2015.pdf [https://perma.cc/ H2M8-VPG7]. Of this, $\$ 39.1$ billion (12.6\%) went to oncology drugs.

68. Cancer Stat Facts: Colorectal Cancer, NAT'L CANCER INST., https://seer .cancer.gov/statfacts/html/colorect.html [https://perma.cc/A5BW-Y29X]. 
has an abysmal prognosis: only $11 \%$ of patients survive for five years. ${ }^{69} \mathrm{~A}$ drug that could cure $\mathrm{mCRC}$, or greatly delay its progression, would be a breakthrough of historic humanitarian significance. So, there should surely be strong incentives for pharmaceutical firms to develop new treatments. And indeed, there are many mCRC drugs on the market that cost exorbitant sums. But these drugs deliver minimal therapeutic benefit.

To see this, consider Figure 1, which compares additional annual spending (above that for previously-standard therapy) 70 to additional therapeutic benefit (measured in months of survival $^{71}$ ) for all FDA-approved, new-generation ${ }^{72}$ drugs for mCRC. ${ }^{73}$ Because pharmaceuticals are typically cheap to produce once manufacturing plants are up and running-in economic terms, their marginal cost is low-their sale prices are good indicators of the rewards they generate for drug makers. ${ }^{74}$ And additional survival time is a good, if imperfect metric of therapeutic benefit.

69. This compares to a $92 \%$ five-year survival rate for Stage I colorectal tumors (which have neither spread to other organs nor grown beyond the inner layers of the colon or rectum). See Surveillance, Epidemiology, and End Results Program, Cancer Stat Facts: Colon and Rectum Cancer, NAT'L CANCER INST., https://seer.cancer.gov/statfacts/html/colorect.html [https://perma.cc/ZZ6T -WYTH]; What Are the Survival Rates for Colorectal Cancer, by Stage?, AM. CANCER SOC'Y, https://www.cancer.org/cancer/colon-rectal-cancer/detection -diagnosis-staging/survival-rates.html [https://perma.cc/ZZ6T-WYTH].

70. We obtained this spending data from GoodRX.com, an online prescription retailer. GOODRX, https://www.goodrx.com/. We used it to estimate the annual cost of treatment for each drug.

71. The survival numbers reported in Figure 1 are averages for all reported clinical trials for each drug. Some of the drugs were tested in multiple clinical trials; for example, panitumumab $\left(V^{2}\right.$ ectibix $\left.^{\circledR}\right)$ was tested in three trials and bevacizumab (Avastin $\left.{ }^{\circledR}\right)$ was tested twice.

72. By "new generation," we mean medications that target particular genes, proteins, or metabolic pathways, as opposed to traditional, much cheaper chemotherapies that kill cells indiscriminately, in rough proportion to their rates of growth.

73. We collected this survival data from completed Phase 3 interventional clinical trials with statistically significant results. In each of these trials, the control was a traditional, oft-used, indiscriminate chemotherapy. See supra note 72. The data in Figure 1 was gathered in August-September 2016 from clinical trials reported at https://www.clinicaltrials.gov/. While drug companies are required to report the results of all clinical trials at clinicaltrials.gov, compliance with this directive is sometimes spotty; accordingly, we might have missed other relevant trials.

74. We would need to factor in sales volumes, of course, to estimate the overall revenue each of these drugs yields for its manufacturer. 


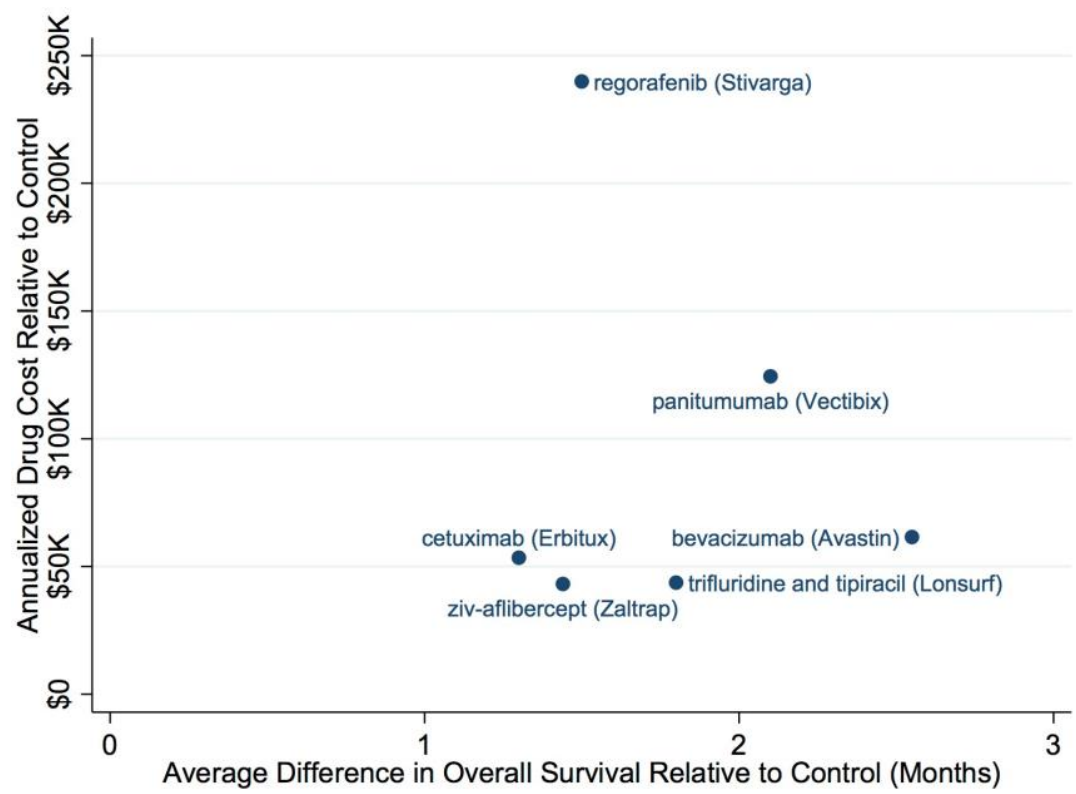

Figure 1: Average Annualized Drug Costs Versus Average Marginal Increase in Overall Survival for Metastatic Colorectal Cancer Treatments Sources: https://www.clinicaltrials.gov and GoodRX.com

Were economic reward tied to therapeutic benefit, we would expect annualized drug cost (on the y axis in Figure 1) to rise with increasing contribution to survival. A line through the six plotted points would slope upwards. But we don't see this; to the contrary, there is no evident relationship between therapeutic benefit and economic reward. Since drug firms set prices based on perceived market conditions, this underscores the weakness or absence of market signals favoring greater therapeutic benefit. ${ }^{75}$

More stunning is the sticker-shock pricing for paltry survival gains that all six plotted points represent. The biggest shocker among the six, regorafenib (Stivarga ${ }^{\circledR}$ ) delivers about 1.5 months additional life expectancy, on average, for an annualized

75. Six plotted points, of course, don't constitute proof, but the absence of a relationship between these six drugs' pricing and therapeutic benefit is consistent with the dynamic we've described. 
cost of almost $\$ 250,000$. Averaging annualized outlays and improvements in life expectancy for all six drugs yields a price tag of $\$ 56,000$ per year for each additional month of survival, or more than $\$ 670,000$ per year for each year of life gained. These numbers understate matters: many $\mathrm{mCRC}$ patients can be expected to take one or more of these drugs for a few or more years. ${ }^{76}$ Data on duration of treatment for each of these drugs is not readily available, ${ }^{77}$ but by way of illustration, a patient who for twenty-seven months paid 78 the above-noted average annual price of $\$ 56,000$ for an additional month of life would incur a cost of more than $\$ 1.5$ million per life-year gained. ${ }^{79}$

The weight of this burden-its opportunity cost for societyis made plain by studies of how people's health and safety choices in non-medical realms translate into dollar values for years of life. ${ }^{80}$ Controversy surrounds these studies' estimates of dollar value-controversy that grows fierce when policymakers rely on them (and explosive when these estimates discount life's value based on diminished quality). ${ }^{81}$ But the values commonly urged for a year of life illuminate the opportunities forgone by spending on these mCRC drugs. Dollar values for a so-called "quality-adjusted life year (QALY)," ${ }^{2}$ calculated by researchers in recent

76. In one study, the mean time from mCRC diagnosis to death was almost three years. Kevin Knopf et al., Survival Outcomes in U.S. Patients with Metastatic Colorectal Cancer: A Retrospective Database Analysis (mCRC), J. CLIN. ONCOLOGY 31, supp. 4 (2013).

77. Ongoing, rapid changes in clinical practice may make it impossible to answer this question.

78. Most patients, of course, don't pay out of pocket (all but the wealthiest among us can't afford these prices); we pay, collectively, through insurance premiums, taxes, and cross-subsidization by health care providers.

79. $\$ 56,000$ (annual price for an additional month of life) $* 27$ months $=$ $\$ 1.512$ million.

80. See generally Milton C. Weinstein et al., QALYs: The Basics, VALUE IN HEALTH, 12, S5-S9 (2009). Risk-related wage differentials and consumers' willingness to pay for safer products are among the metrics employed to attach dollar values to years of life.

81. See generally Peter J. Neumann, What's Next for QALY's?, 305 J. AM. MED. Ass'N 1806 (2011); John Rawls, Castigating QALYs, 15 J. MED. ETHICS 143 (1989) (outlining criticisms of QALYs).

82. Calculation of QALYs discounts years of life gained, or saved, by a factor that supposedly expresses the diminished value of lives lived in states of impaired health. Weinstein et al., supra note 80. 
years, range from $\$ 50,000$ to $\$ 200,000^{83}$-about $\$ 4,200$ to $\$ 16,700$ per month.

The above-estimated costs for a year (or a month) of life gained from new-generation $\mathrm{mCRC}$ therapies dwarf these QALY values. One can quibble with our cost estimates but not with the reality that these costs far exceed calculated QALY values: our average annualized cost of $\$ 56,000$ for a month of life ${ }^{84}$ is more than three and one-third times greater than the maximum commonly-proposed value for a QALY. ${ }^{85}$

Disproportionate costs for minimal, even nonexistent therapeutic benefits are endemic in cancer therapy more generally. 86 And oncology's upward pressure on medical spending is expected to intensify as high-priced oncology drugs occupy a growing share of the pharmaceutical market. 87

Many of these drugs reflect genuine scientific advances, however marginal their clinical benefits. But most of the prescription medications approved by the FDA in recent decades are

83. See Peter J. Neumann et al., Updating Cost-Effectiveness-The Curious Resilience of the \$50,000-per-QALY Threshold, 371 N. ENG. J. MED. 796, 79697 (2014).

84. Supra text accompanying note 79 .

85. Id. Moreover, since metastatic colorectal cancer is a grave illness, proponents of the QALY approach would discount these drugs' longevity gains, boosting the drugs' cost-per-QALY above their cost per actual life-year gained.

86. Consider Genentech's drug Avastin ${ }^{\circledR}$ (bevacizumab). Touted as a major breakthrough in treating metastatic non-squamous non-small cell lung cancer, this drug extends the life expectancy of late-stage lung cancer patients by just two months-from 10.3 to 12.3 months. Eric Budish et al., Do Firms Underinvest in Long-Term Research? Evidence from Cancer Clinical Trials, 105 AM. ECON. REV. 2044, 2045 (2015). Another recent study estimated that for the seventy-one drugs approved by the FDA for solid tumors between 2002 and 2014, median gains in progression-free and overall survival were a mere 2.5 and 2.1 months, respectively. Tito Fojo et al., Unintended Consequences of Expensive Cancer Therapeutics-The Pursuit of Marginal Indications and a Me-Too Mentality That Stifles Innovation and Creativity, 140 J. AM. MED. Ass'N OTOLARYNGOLOGY-HEAD \& NECK SURGERY 1225, 1227 (2014) (concluding that only thirty (42\%) of the seventy-one drugs achieved "clinically meaningful improvements").

87. IMS INST. FOR HEALTHCARE INFORMATICS, GLOBAL MEDICINES UsE IN 2020: OUTLOOK AND IMPLICATIONS (2015), https://www.iqvia.com/-/media/ iqvia/pdfs/institute-reports/global-medicines-use-in-2020 [https://perma.cc/ JXK4-9N5M] (predicting that one-third of all new drugs introduced by 2020 will treat cancer). 
so-called "me-too" drugs, 88 belonging to the same chemical category and sharing the same molecular mechanism as previouslyintroduced medications. ${ }^{89}$ These drugs deliver no additional therapeutic value. 90 The resources devoted to developing and marketing them are almost entirely wasted. ${ }^{91}$ Pharmaceutical firms' success in selling patent-protected "me-too" medications for prices much higher than those for generic originals in the same categories demonstrates the power of even dubious claims of benefit-and the cost these claims impose.

Much attention has been paid to a report from the Institute of Medicine (IOM) concluding that $30 \%$, or $\$ 750$ billion, of what the U.S. spent on health care in 2009 was wasted. 92 (Adjusted for subsequent increases in medical spending, this figure would be more than $\$ 1$ trillion.) Fraud, overpricing, and pointless administrative expense captured headlines. ${ }^{93}$ But as much as half

88. See NDA Approvals by Therapeutic Potential and Chemical Type, U.S. FOOD \& DRUG ADMIN., https://web.archive.org/web/20090720060525/http:// www.fda.gov/Drugs/DevelopmentApprovalProcess/HowDrugsareDevelopedand Approved/DrugandBiologicApprovalReports/ucm121102.htm [https://perma.cc/ H29G-AXES] (last updated Dec. 31, 2004) (reporting that 58\% of the 248 new molecular entities approved by the FDA between 1990 and 2004 were me-too drugs).

89. Stephane Régnier, What Is the Value of 'Me-Too' Drugs?, 16 HEALTH CARE MGMT. SCI. 300, 300 (2013). A more recent study from the Institute for Quality and Efficiency in Health Care (IQWiG) - a German health technology assessment agency charged with investigating the marginal benefit of new drugs over the standard of care-concluded that " $[\mathrm{m}]$ ore than half of new drugs in Germany lack proof of added benefit over existing treatments." Beate Wieseler et al., New Drugs: Where Did We Go Wrong and What Can We Do Better?, BRITISH MED. J., July 10, 2019, at 1, 4.

90. Régnier, supra note 89 . To be sure, a patient may be allergic to one but not another drug in the same chemical class; moreover, differences in drug absorption or metabolism may matter clinically, making "me-too" molecules occasionally useful.

91. Not only do additional drugs in a class often add minimal therapeutic value; the claim that they yield economic value through price competition is arguably mythic as well. See, e.g., Nicole M. Gastala et al., Medicare Part D: Patients Bear the Cost of "Me Too" Brand-Name Drugs, 35 HeAlTH AFF. 1237, 1237 (2016) (noting that therapeutically equivalent "me-too" medications are often prescribed and cost significantly more than cheaper generic medications).

92. Inst. of Med., Best Care at Lower Cost: The Path to ContinuOUSly LeARning HeAlth CARE IN America 101-02 (Mark Smith et al. eds., 2013).

93. E.g., Alex Wayne, Health System in U.S. Plagued by $\$ 765$ Billion in Waste, BLOOMBERG (Sept. 6, 2012, 10:02 AM), https://www.bloomberg.com/ 
of this waste, ${ }^{94}$ according to the IOM, is care that yields no therapeutic benefit. ${ }^{95}$ Some of this care is clearly useless-e.g. redundant tests, or interventions that defy scientific proof of their pointlessness. But much is futile only after the fact: it's plausible in advance for the doctors who order it to suspect that it might produce some benefit. Its enormous expense is the price of our national unwillingness to forgo even tiny chances of therapeutic advantage, especially when threats to health loom imminently.

We don't mean, in this Article, to condemn this national trait. To the contrary, we have argued that uncompromising use of available rescue technologies is inevitable, even at times noble ${ }^{96}$ - and embedded in our psychology, culture, and ethics, as well as stakeholders' settled expectations. Rather, we mean to highlight the steep price, in opportunities forgone, that we pay for our clinical aggressiveness. Dollar values calculated for QALYs reflect the tradeoffs people make beyond the medical realm, between health and other wants and needs. Medical expenditures that "buy" health outcomes at prices higher than what people are wont to pay for equivalent health outcomes outside the hospital or doctor's suite ${ }^{97}$ crowd out alternative, highervalue uses of the money spent.

Such medical expenditures are consonant with the psychology of rescue-in this sense, they deliver value that the QALY metric fails to capture-but they bleed society of value that people would otherwise prefer. If there's a way to fulfill our longing for medical rescuers' best efforts at reduced cost to our other aims, we should choose it. This Article contends that there is.

news/articles/2012-09-06/u-s-health-system-must-be-re-engineered-iom-panel -says [https://perma.cc/EWY5-N39T].

94. This portion totals more than half if one includes the overpricing and administrative spending associated with it. See INST. OF MED., supra note 92, at 102.

95. Id.

96. Supra text accompanying notes $48-50$.

97. We can also calculate a treatment's incremental cost-effectiveness ratio (ICER), which is the ratio of incremental costs to incremental benefits: $I C E R=\frac{C_{1}-C_{0}}{E_{1}-E_{0}}$, with the effectiveness parameter usually measured in QALYs. For example, a therapy that costs $\$ 50,000$ more than the best alternative and that extends life by two more months (with full health) than does this alternative would have an ICER of $\$ 50,000 /(2 / 12)=\$ 300,000 /$ year-much greater than even the highest empirically-based estimates of the value of a QALY. 


\section{A Doctors' Plot?}

Some have argued that physicians impose the ethic of uncompromising loyalty to patients in collusive, self-serving fashion, and that many consumers would, if given the chance, choose to pay less for health plans that require doctors to forgo pricey, maximally-beneficial care to save money. 98 This begs the question of why insurers haven't offered such plans. Surely, if they saw a market for such low-end coverage, they would have pressed to do so. Prior to the ACA's passage, nationwide minimum-benefit requirements ${ }^{99}$ didn't stand in the way. And surely, the several large health plans with national reach and tens of millions of subscribers could marshal their enormous purchasing power to negotiate concessions from physicians willing to trade fealty to the clinical state-of-the-art for access to large pools of patients. ${ }^{100}$

That insurers haven't done so-that they've never explicitly challenged the Hippocratic ideal (however much they've pushed back against it covertly ${ }^{101}$ ) is, we think, the product not of illicit economic collusion but of the mutually reinforcing influence of patients' psychological needs, society's deep-rooted expectations, and the profession's long-standing values. It is also, we will argue presently, a product of law.

\section{B. LAW AND THE NEGLECT OF COST}

Law, as well, reflects and reinforces the ethic of rescue, the Hippocratic ideal, and neglect of cost. Multiple common-law and statutory regimes push in the same direction, away from the bal-

98. E.g., Clark C. Havighurst, Health Care Choices: Private ConTRACTS AS INSTRUMENTS OF HEALTH REFORM 228-29 (1995); Mark A. Hall, Rationing Health Care at the Bedside, 69 N.Y.U. L. REV. 693, 699-700 (1994).

99. Larry Levitt et al., Questions About Essential Health Benefits, KAISER FAM. FOUND. (Oct. 18, 2011), https://www.kff.org/health-reform/perspective/ questions-about-essential-health-benefits/ [https://perma.cc/E4SR-WF6Q].

100. See Erin E. Trish \& Bradley J. Herring, How Do Health Insurer Market Concentration and Bargaining Power with Hospitals Affect Health Insurance Premiums?, 42 J. HEALTH ECON. 104, 113 (2015) (describing how insurers could use leverage with providers to lower insurance premiums).

101. See generally M. Gregg Bloche, Trust and Betrayal in the Medical Marketplace, 55 STAN. L. REV. 919 (2002) (discussing insurers' use of financial incentives to nudge physicians away from the Hippocratic ethic of undivided commitment to their patients' well-being). 
ancing of therapeutic benefit against economic burden and toward all-out deployment of existing clinical resources. Medical tort law and the ACA's "independent review" scheme ${ }^{102}$ for resolution of disputes over insurance coverage exert great force in this regard. They're backed up by the ACA's explicit prohibition of both "rationing"103 and the use of "quality-adjusted life years"104 (QALYs) in the development of federal health-care payment policy—and by Medicare's statutory separation of coverage determinations and payment rates for clinical services. ${ }^{105}$

\section{Medical Tort Law}

The law of negligence calls upon actors to take care so long as the expected benefits of doing so outweigh the costs of not doing so. ${ }^{106}$ In pursuit of this idea, negligence law often looks to industry standards for rules of conduct; 107 the rationale for this is that industry practice in well-functioning markets reflects the optimal balance of benefit and cost108_-"reasonable care." 109 As every first-year law student learns, negligence doctrine calls for courts to disregard industry standards when markets don't reflect this optimal balance-when, in Learned Hand's iconic language, "a whole calling may have unduly lagged ...."110 Judges have done so in many specialized fields, ${ }^{111}$ typically imposing

102. 42 U.S.C. $\$ 300 g g-19(2012)$.

103. 42 U.S.C. $§ 299 b-37(a)(2)(B)$ (2012) (stating that the findings of the Patient Centered Outcomes Research Institute shall "not be construed as mandates, guidelines, or recommendations for payment, coverage, or treatment").

104. 42 U.S.C. 1320e-1(e) (2012).

105. Compare 42 U.S.C. 1395y(l)(1) (2012) (granting the Secretary of Health $\&$ Human Services the authority to determine covered expenses that are "reasonable and necessary"), with 42 U.S.C. 1395w-4(b) (2012) (directing the Secretary to establish fee schedules based on the service's "relative value," "conversion factor," and "geographic adjustment factor").

106. E.g., RESTATEMENT (SECOND) OF TORTS $§ 291$ (AM. LAW INST. 1965).

107. Gideon Parchomovsky \& Alex Stein, Torts and Innovation, $107 \mathrm{MICH}$. L. REV. 285, 291 (2008).

108. See Louis Kaplow \& Steven Shavell, Property Rules Versus Liability Rules: An Economic Analysis, 109 HARV. L. REV. 713, 725 (1996) (discussing damage calculations based on prevention costs and resulting harm).

109. RESTATEMENT (THIRD) OF TORTS: LiAB. FOR PHySiCAL \& EMOTIONAL HARM $§ 3$ (AM. LAW INST. 2005); RESTATEMENT (SECOND) OF TORTS $§ 282$ (AM. LAW INST. 1965).

110. The T.J. Hooper, 60 F.2d 737, 740 (2d Cir. 1932).

111. Parchomovsky \& Stein, supra note 107. 
levels of care higher than industry norms.112 But for medicine, deference to professional standards has been the rule, ${ }^{113}$ despite the role of insurance in driving the intensity of care to levels not justifiable in cost-benefit balancing terms. ${ }^{114}$

Tort law thus powerfully reinforces professional norms ${ }^{115}$ and the aforementioned psychological, cultural, economic, and ethical influences that shape them-by putting physicians who breach them at risk for career-altering liability. Indeed, the tort system likely boosts clinical spending by a few to several percentage points, since some doctors appear to react to their fear of liability by ordering tests and treatments they wouldn't otherwise prescribe. ${ }^{116}$

\section{Coverage Disputes and Independent Review}

By 2010, when the ACA became law, all but seven states had enacted external review schemes to resolve disputes between patients and health insurers over whether care should be covered. ${ }^{117}$ The ACA made such review near-universal, 118 imposing

112. See Richard A. Epstein, The Path to The T.J. Hooper: The Theory and History of Custom in the Law of Tort, 21 J. LEGAL STUD. 1, 38 (1992) ("It is always open season on an established practice ....").

113. This deference has evolved-the second half of the twentieth century saw courts in many jurisdictions move from local to national standards of care. Alex Stein, Toward a Theory of Medical Malpractice, 97 IOWA L. REV. 1201, 1210 (2012). Some states permit multiple clinical standards (e.g., adopting the "respectable minority" rule, which allows alternative standards so long as some respected practitioners adhere to them). Id. at 1212-13.

114. See supra text accompanying notes 38-40.

115. See Sara C. Charles et al., Physicians on Trial-Self-Reported Reactions to Malpractice Trials, 148 W. J. MED. 358, 359 (1988) (illustrating physician behavior changes after being sued).

116. Michelle M. Mello et al., National Costs of the Medical Liability System, 29 HEALTH AFF. 1569, 1572-73 (2010). This effect on medical spending is more modest than that claimed by advocates of damage caps and other limits on malpractice liability; indeed, some of these advocates inaccurately insist that malpractice liability is a main driver of rising clinical spending. E.g., Sebastian Panthöfer, Do Doctors Prescribe Antibiotics Out of Fear of Malpractice? 6 (Univ. of York Health, Econometric \& Data Grp., Working Paper No. 16/31, 2016), https://www.researchgate.net/publication/309592434_Do_Doctors_Prescribe_ Antibiotics_Out_of_Fear_of_Malpractice [https://perma.cc/3KQZ-BZKZ].

117. Wade S. Hauser, Does Iowa's Health Care External Review Process Replace Common-Law Rights?, 99 IowA L. REV. 1401, 1405-06 (2014).

118. Only so-called "grandfathered health plans," plans purchased on the individual market before March 23, 2010, are exempt from the ACA's external 
nationwide requirements that, in practice, lock in professional standards of care as benchmarks for what insurers should cover. ${ }^{119}$ Health plans depart from these professional practice norms at their peril. To be sure, health plans frequently take this risk: external reviewers' reversals of coverage denials approach, or even exceed, $50 \%{ }^{120}$ in some states. ${ }^{121}$ Plans have powerful incentives to take this gamble. They needn't pay compensatory damages or any other penalty when they lose: they are responsible only for covering the services for which they'd earlier refused to pay. ${ }^{122}$ And coverage denials that patients don't challenge are financial "wins" for health plans even when the forgone challenges would succeed. ${ }^{123}$ But plans achieve these financial gains

review requirements. U.S. CTRS. FOR MEDICARE \& MEDICAID SERVs., Grandfathered Health Plan, HEALTHCARE.GOv, https://www.healthcare.gov/glossary/ grandfathered-health-plan/ [https://perma.cc/6A3N-QFVC]; Guidance on External Review for Group Health Plans and Health Insurance Issuers Offering Group and Individual Health Coverage, and Guidance for States on State External Review Processes, U.S. DEP'T LABOR: EMP. BENEFITS SEC. ADMIN. (June 22, 2011), https://www.dol.gov/sites/dolgov/files/EBSA/employers-and-advisers/ guidance/technical-releases/11-02.pdf [https://perma.cc/3VXB-9C3D].

119. 42 U.S.C. $§ 300$ gg-19 (2012). It achieves this by adopting the "consumer protections" set forth in a model state statute, the Uniform Health Carrier External Review Model Act, developed by the National Association of Insurance Commissioners (NAIC). UNIFORM HEALTH CARRIER EXTERNAL REVIEW MODEL ACT (NAT'L ASS'N OF INS. COMM'RS), https://www.naic.org/documents/ committees_b_uniform_health_carrier_ext_rev_model_act.pdf [https://perma .cc/HXR7-CHBQ] (instructing reviewers to give weight to treating physicians' recommendations, clinical practice guidelines promulgated by specialty societies, and other professional authorities).

120. See, e.g., Pauline Bartolone, Patients Win About Half the Time They Challenge Denied Health Care Services, CAP. PUB. RADIO (Apr. 1, 2014), http:// www.capradio.org/articles/2014/04/01/patients-win-about-half-the-time-they -challenge-denied-health-care-services/ [https://perma.cc/36GB-UZUC] (reporting external-appeal success rates of fifty-one to fifty-seven percent for California patients who challenged coverage denials by four large health plans between 2006 and 2012).

121. Karen Pollitz et al., Claims Denials and Appeals in ACA Marketplace Plans, KAISER FAM. FOUND. (Feb. 25, 2019), https://www.kff.org/health-reform/ issue-brief/claims-denials-and-appeals-in-aca-marketplace-plans/ [https:// perma.cc/3HFM-ZRNX].

122. Appealing Health Plan Decisions, U.S. DeP'T Health \& Human SERVs., https:/www.hhs.gov/healthcare/about-the-law/cancellations-and-appeals/ appealing-health-plan-decisions/index.html [https://perma.cc/Z6TU-63CV].

123. More Consumers Could Benefit from Independent External Review, NAT'L ASS'N OF INDEP. REV. ORG. (Aug. 24, 2017), https://www.nairo.org/2017 -08-24-more-consumers-could-benefit-from-independent-external-review/. 
on the down-low. These "wins" send no signal to health care providers to economize on care, aside from the prospect of needing to do paperwork to file an external appeal. The main message from the ACA's external-review requirement, a requirement that applies to almost all employment-based and individually-purchased coverage (and thus to the vast majority of privately-insured Americans), is that professional standards of care govern-standards shaped by the ethic of rescue, the Hippocratic ideal, and disregard for cost.

\section{FDA Criteria for New Drugs and Medical Devices}

By statute, the Food and Drug Administration (FDA) is obligated to allow sale and use of new prescription drugs and medical devices upon a showing that they are safe and effective. ${ }^{124}$ Neither the FDA's enabling legislation nor its mechanisms for judging safety and effectiveness permit the agency to consider therapeutic value relative to cost. ${ }^{125}$ As a result, even a tiny therapeutic benefit that a new drug or device achieves for a small subpopulation of those upon whom the product is tested suffices to show that it is "safe and effective," so long as an FDA-approved clinical trial establishes that the benefit is statistically significant. ${ }^{126}$ A manufacturer need not even show that its new product is superior to the status quo; so-called "me-too" drugs and devices routinely enter the market in this manner. ${ }^{127}$

Once the FDA approves a new drug or device, the manufacturer can promote even the smallest of marginal advantages to patients ${ }^{128}$ and physicians. Sometimes, patients ask for the new

124. See 21 U.S.C. § 355(d) (2012).

125. See, e.g., id. (describing grounds for refusal of new drug applications, with safety and effectiveness as the primary standards; no mention of cost analysis is included).

126. Statistical significance is defined, by convention, as a less than $5 \%$ probability that a finding is the product of chance. Supra text accompanying note 64. Drug and device makers have finely honed the craft of spotting subpopulations that show some benefit even when the overall set of patients enrolled in a controlled trial does not.

127. NDA Approvals by Therapeutic Potential and Chemical Type, supra note 88.

128. Promotion of prescription drugs and devices directly to patients has had growing influence on sales over the past twenty years, owing to the FDA's relaxation of regulatory constraints on so-called "direct-to-consumer" (DTC) advertising. David Lazarus, Ask Laz: Direct-to-Consumer Drug Ads: A Bad Idea That's About to Get Worse, L.A. TIMES (Feb. 15, 2017, 9:25 AM), https://www 
product and physicians then prescribe it;129 other times, physicians spur the product's adoption in response to companies' promotional efforts. ${ }^{130}$ Moreover, while federal law criminalizes manufacturers' promotion of drugs and devices for uses that the FDA hasn't authorized, ${ }^{131}$ physicians (including those who receive financial benefits from drug or device makers) are permitted to promote unapproved uses, even absent evidence of therapeutic benefit. The upshot is that the law governing FDA approval of new drugs and devices locks open multiple pathways to adoption of technologies that yield statistically significant but therapeutically small (and, for unapproved uses, sometimes nonexistent) benefits, often at great cost. 132

\section{Patent Law and Drug Companies' Reach for Mediocrity}

Our current patent system largely magnifies rather than mitigates the distortion we identify here. This shouldn't be the case - after all, the whole purpose of patent law is to incentivize new and useful inventions. ${ }^{133}$ In theory, patent law does this by making it easier for putative inventors to earn private returns

.latimes.com/business/la-fi-lazarus-drugadvertising-20170215-story.html [https://perma.cc/74T7-4Z9N].

129. Both market pressure (to satisfy patients) and Hippocratic obligation to provide all beneficial care push physicians to do so. Robert J. Marder, The Opioid Epidemic: Patient Satisfaction and Physician Prescribing, HEALTHLEADERS (Sept. 18, 2017), https://www.healthleadersmedia.com/strategy/opioid-epidemic -patient-satisfaction-and-physician-prescribing [https://perma.cc/7AKR-5PYH] (describing the growing market pressure on physicians to achieve high patientsatisfaction ratings, which can yield more referrals and bigger fees); infra text accompanying notes 165-74.

130. Jerry Avorn, Powerful Medicines: The Benefits, Risks, AND COSTS OF PRESCRIPTION DRUGS (2004).

131. 21 U.S.C. $§ 355(a)$ (2012) ("No person shall introduce or deliver for introduction into interstate commerce any new drug, unless an approval of an application filed pursuant to subsection (b) or (j) of this section is effective with respect to such drug.").

132. Note that this cost isn't only the expense of manufacturing the drug or device (plus the profits accruing to firms' owners); it includes the opportunity cost, for society, of firms' failure to devote their R\&D resources to projects with greater therapeutic potential.

133. See Alan Devlin \& Neel U. Sukhatme, Self-Realizing Inventions and the Utilitarian Foundation of Patent Law, 51 WM. \& MARY L. REV. 897, 914 (2009) (describing the utilitarianism behind patent law to promote socially-beneficial inventions). 
on inventions that would otherwise not be profitable. ${ }^{134}$ And basic economic theory suggests that inventions that generate private returns should generally also create social value, since people would otherwise not purchase the product sold by the patentee. ${ }^{135}$

While this assumption might be reasonable in a typical market, this logic is often turned on its head in the realm of medical innovation. The problem here is that private value is often not aligned with social value; this in turn means patent law might not promote socially optimal outcomes in this setting.

This problem manifests itself most directly in the projects that putative inventors choose to pursue. Specifically, current patent law might distort firm incentives, causing them to pursue projects that have lower social value but higher private returns. ${ }^{136}$ And by pursuing an invention that maximizes her private returns, the inventor might crowd out investment in other projects that would generate a larger social return. ${ }^{137}$ Put differently, while patent law might make many different inventions profitable, it might not tilt inventors' preferences toward the most socially valuable ones.

The following numerical example helps illustrate the point. Suppose a company is deciding whether to invest in one of two projects: a "low-value" project that delivers $\$ 1$ million in social value with a $90 \%$ chance of success, and a "high-value" project

134. Patents create private value by solving a well-known public goods problem. It often costs substantial time, money, and effort to create a new invention and turn it into a commercially viable product. Patents are a limited, legal monopoly we award to inventors that enables them to recover these costs. Without patents, we worry about free-riding, where a competitor copies an innovation once it's sold or otherwise publicly available and incorporates it into a competing product, thereby eating into the innovator's profits. A patent heightens an innovator's private return on her creation, allowing her to recoup more of her R\&D investment and thereby encouraging her to create the invention in the first place.

135. See, e.g., ANDreu Mas-Colell ET Al., Microeconomic Theory 318 (1995) (stating that in a competitive equilibrium, price will not exceed a consumer's marginal utility).

136. Michele Boldrin \& David K. Levine, The Case Against Patents, $27 \mathrm{~J}$. ECON. PERSP. 3, 7 (2013) (arguing that patent systems discourage innovation because of the legal actions confronting potential inventors). See generally Heidi L. Williams, How Do Patents Affect Research Investments?, 9 ANN. REV. ECON. 441,445 (2017) (surveying empirical studies on the effect of patent law on public and private research investments).

137. See Devlin \& Sukhatme, supra note 133. 
that delivers $\$ 8$ million in social value with a $50 \%$ chance of success. Both projects deliver nothing if they fail, and assume (for simplicity), the company keeps the entire social value of whatever project it chooses. Which project will the firm select?

The firm's expected returns from the two projects are:

$\$ 1$ million $* 0.90=\$ 900,000$, for the low-value project, and

$\$ 8$ million $* 0.50=\$ 4,000,000$, for the high-value project.

A risk-neutral firm would select the high-value, socially optimal project, as it delivers more private value.

Now instead assume the firm receives $\$ 9$ million in private value for any new technology that improves upon the status quo, even if it creates almost no additional social value. Then the firm's expected returns become:

$.90 *(\$ 1$ million $+\$ 9$ million $)=\$ 9$ million, for the lowvalue project, but only:

$.50 *(\$ 8$ million $+\$ 9$ million $)=\$ 8.5$ million, for the highvalue project.

Here, the firm will choose the low-value project, even though it generates less social value. Note this is true even though the firm would earn more ( $\$ 17$ million) if it chose the high-value project and was successful.

What motivates the change in the firm's project choice toward the low-value (socially suboptimal) project? The driving force is the $\$ 9$ million in private returns that the firm receives for improving upon the status quo, however barely. Namely, the firm is skewed toward the low-value invention because that project is less risky and the firm's guaranteed payment for exceeding the status quo is high enough that it does not want to bear the additional risk inherent in pursuing the high-value invention.

Indeed, the reality is worse than this: the private return for drug developers often bears minimal relation to the therapeutic value of a clinical intervention, so the developer captures less of the social value as it increases. ${ }^{138}$ This results in a "flatter" slope when graphing private value versus social value, similar to that apparent from the mCRC treatments graphed in Figure 1. So in

138. See Laura Entis, Why Does Medicine Cost So Much? Here's How Drug Prices Are Set, TIME (Apr. 9, 2019), https://time.com/5564547/drug-prices -medicine/?amp=true [https://perma.cc/8N5H-NY44] (describing drug price tiers, which are primarily based on manufacturers' willingness to offer discounts to pharmacy benefit managers rather than on the drugs' effectiveness). 
our example, if the firm recovers $100 \%$ of the social value for the low-value invention but only $50 \%$ of the social value for the highvalue invention, then the private boost would only need to exceed $\$ 2.75$ million in order to induce the firm to pick the socially suboptimal, low-value project. 139

In the pharmaceutical context, these less risky, low-value inventions typically correspond to me-too drugs. From a scientific perspective, me-too drugs are often less risky to pursue because their chemical structure and mechanism of action is similar to existing drugs. From an expected demand perspective, metoo drugs are also less risky because consumers have already revealed whether there is demand for a similar drug on the market, so putative manufacturers have more information about their likely profits.

So it's no wonder why drug companies continue to seek out me-too innovation. There is less reason for them to reach for higher-value, but riskier, research projects that potentially provide greater social benefit. ${ }^{140}$ Rather, firms plow money into projects that yield low social value but are less risky and provide high private returns. ${ }^{141}$

Moreover, even if me-too drugs and other marginal innovation offer some benefits, we need to ask whether those benefits

139. We get $\$ 2.75$ million by solving for $\mathrm{X}$ in the following equation: ( $\$ 8$ million*0.50) $+\$ \mathrm{X}$ million $) * 0.50=(\$ 1$ million $+\$ \mathrm{X}$ million $) * 0.90$.

140. In related work, one of the co-authors formally models how current market dynamics incentivize firms to pursue marginal innovation over breakthrough technologies. See Son Le \& Neel U. Sukhatme, Reaching for Mediocrity: Competition and Stagnation in Pharmaceutical Innovation (July 12, 2019) (unpublished manuscript) (on file with authors).

141. David Abrams and others have investigated the relationship between a patent's private and social value by examining whether a patent's forward citations - the number of times it is cited by future patents - correlates with its private value. Using data from non-practicing entities, they find that there is an inverted-U relationship between citations and value-value increases with citations for a while, and then decreases as forward citations become very frequent. See David S. Abrams et al., Patent Value and Citations: Creative Destruction or Strategic Disruption?, (Penn Law: Legal Scholarship Repository) (Nov. 5, 2013), https://scholarship.law.upenn.edu/cgi/viewcontent.cgi?article =1497\&context=faculty_scholarship [https://perma.cc/39PW-VTRB].

Our discussion here does not contradict their results-private value and social value might be correlated for drugs and medical technology. But this correlation is weak, and firm decision-making is skewed toward lower-value innovations because firms receive a large fixed "boost" for any invention that exceeds the status quo. 
justify the social costs they impose. Most importantly, these include opportunity costs - the drugs that pharmaceutical companies might have developed but chose not to because they devoted resources to developing a me-too drug instead. If the average cost of developing a new drug is $\$ 1$ billion, as is commonly asserted, ${ }^{142}$ perhaps that money might have been better spent elsewhere than on me-too products. If so, me-too innovation is crowding out other innovation that would be more socially valuable.

5. The ACA's Prohibitions Against "Rationing" and the Use of "Quality-Adjusted Life Years"

As the political battle that preceded the ACA's passage built to a crescendo, opponents tried to cast the law as a covert scheme to ration Medicare. ${ }^{143}$ Worried ACA drafters tried to deflect this attack by adding explicit prohibitions. An HHS panel conceived to develop cost-control strategy for Medicare in the event that the program broke through annual growth ceilings ${ }^{144}$ was as a result barred from issuing "any recommendation to ration healthcare."145 The law's authors also added language prohibiting federally-funded clinical outcomes researchers ${ }^{146}$ and Medicare administrators from "develop[ing] or employ[ing] a dollars-

142. Joseph A. DiMasi et al., Innovation in the Pharmaceutical Industry: New Estimates of R\&D Costs, 47 J. HEALTH ECON. 20, 22 (2016). This proposition, which incorporates assumptions about opportunity costs and inflation and discount rates, is much disputed. Costs to Bring a Drug to Market Remain in Dispute, MANAGED CARE (Sept. 14, 2017), https://www.managedcaremag.com/ news/20170914/costs-bring-drug-market-remain-dispute [https://perma.cc/ 7QYE-N2H3].

143. See Igor Volsky, Health Debate 2.0: Republicans Attack Obama for 'Rationing' Care with IPAB Commission, THINKPROGRESS (Apr. 14, 2011, 5:20 PM), https://thinkprogress.org/health-debate-2-0-republicans-attack-obama-for -rationing-care-with-ipab-commission-1eb62c64041c/ [https://perma.cc/6G6S -NZ3G] (discussing the opposition's critique of the ACA's so-called "death panel").

144. Affordable Care Act (ACA), Pub. L. No. 111-148, § 3403, 124 Stat. 119, 489-507 (2010) (repealed 2018) (establishing the Independent Medicare Advisory Board, which had authority to impose Medicare cost-containment practices, including changes in how healthcare providers are paid, subject to congressional veto). In the event that Medicare's projected per-capita growth exceeded growth ceilings, the HHS Secretary was required to impose the costcontainment policies the Board proposed, unless Congress enacted an alternative approach. $I d$. at $489-94$.

145. Id. at 490 .

146. The ACA created a new federal agency, the Patient Centered Outcomes Research Institute (PCORI), to fund research into the comparative effectiveness 
per-quality adjusted life year" or "similar measure" as a "threshold" for determining "cost[-]effective[ness]," coverage, or payment. ${ }^{147}$

"Rationing" has no clear legal definition beyond the term's past use, most famously during World War II, to refer to regulatory mechanisms for distributing goods when demand exceeds supply. ${ }^{148}$ But in the health care context, the U.S. Supreme Court has used the term sweepingly, to characterize all withholding of clinical services that might provide any net therapeutic benefit, whether the withholding occurs via regulatory, market, or other means. ${ }^{149}$ Read this way, the ACA's prohibition against Medicare rationing bars all cost-containment policies that forgo potential therapeutic benefit, a proscription in keeping with the public expectations and professional ideals we've discussed.

Even so, the Medicare cost-control panel, the Independent Payment Advisory Board (IPAB), was repeatedly condemned as a "rationing board." 150 Bipartisan opposition led to its repeal in 2018. ${ }^{151}$ Rather than being a breakthrough in the fifty-year quest to contain Medicare spending, the IPAB was an object lesson in the political hazards of even seeming to say "no" to care that might yield some net benefit.

The proscription against Medicare's use of quality and years of life to value medical services poses yet another barrier to the weighing of benefit against cost. This prohibition makes health care literally priceless as a matter of Medicare law: it commands

of alternative clinical interventions. Some ACA opponents charged that PCORI's hidden agenda was healthcare rationing, based on judgments about quality of life. Julie Appleby, New Group to Set Priorities for Medical Effectiveness Research, KAISER HEALTH NEWS (Jan. 16, 2012), https://khn.org/news/ comparative-effectiveness-health-care-pcori/ [https://perma.cc/8DYB-98H5].

147. ACA, $\S 6301$.

148. World War II Rationing, U.S. HISTORY, https://www.u-s-history.com/ pages/h1674.html [https://perma.cc/D97B-E5BT].

149. Pegram v. Herdrich, 530 U.S. 211, 220 (2000).

150. Jennifer Haberkorn \& Ginger Gibson, Ryan Targets "Rationing Board," POLITICO (Aug. 21, 2012, 10:41 AM), https://www.politico.com/story/2012/08/ ryan-puts-rationing-board-in-the-crosshairs-079934?paginate=false [https:// perma.cc/WMZ7-22R5].

151. Margot Sanger-Katz, Another of Obamacare's Unloved Provisions Is Gone, N.Y. TIMES (Feb. 9, 2018), https://www.nytimes.com/2018/02/09/upshot/ obamacare-ipab-medicare-congress.html [https://perma.cc/ZC8V-PU9E]. 
that care yielding any potential benefit be covered and paid for without regard for the magnitude of this benefit.

The ACA's proscription against developing cost-effectiveness measures that take life-expectancy and quality-of-life gains into account has even broader reach-to all Americans with private insurance, as well as to those covered through Medicare and Medicaid. The Patient Centered Outcomes Research Institute (PCORI), the agency created by the ACA to plan and pay for studies of tests' and treatments' comparative effectiveness, is the biggest funder of such research. ${ }^{152}$ This research is a classic "public good" in the economics sense, ${ }^{153}$ supplied at suboptimal levels by health care providers, insurers, and other market actors. ${ }^{154}$ Stifling PCORI's ability to compare the cost-effectiveness of alternative diagnostic and therapeutic approaches shrinks the evidence base concerning clinical value available to all health care payers, public and private.

6. Medicare's Separation of Decisions About Coverage and Payment

Another obstacle to Medicare's consideration of cost has its origins in the program's original design. Medicare's drafters created separate schemes for deciding whether a clinical service or product should be covered and determining how much the government should pay for it. ${ }^{155}$ The former scheme requires Medi-

152. Appleby, supra note 146.

153. Public Goods-The Economic Lowdown Podcast Series, FED. RES. BANK ST. LOUIS (Mar. 25, 2015), https://www.stlouisfed.org/education/economic -lowdown-podcast-series/episode-17-public-goods [https://perma.cc/6WEK

-A38R]. A public good is nonexcludable, meaning everyone may consume it, and nonrivalrous, meaning “one person's consumption does not hinder anyone else's consumption of the good." Id.

154. Health care providers and drug- and device-makers have suboptimal economic incentives to do high-quality comparative-effectiveness research since they gain more in the marketplace by promoting their products than by doing studies that might show their services and products to be inferior. And private insurers have insufficient incentives to perform this research since doing so yields insufficient competitive advantage. If the research is published (or otherwise made public), all insurers will be able to use it. But if the insurer that performs it keeps the findings (and ensuing payment protocols) proprietary, denials of coverage on the basis of these findings will breed distrust, undermining the insurer's business.

155. 42 U.S.C. $§ 1395 y(l)(1)$ (2012) (describing covered expenses as those that are "reasonable and necessary"); 42 U.S.C. § 1395w-4(b) (2012) (describing 
care to cover care it deems "reasonable and necessary" (a standard borrowed from private insurance contracts)-language that Medicare's administrators have never construed to permit the weighing of costs. ${ }^{156}$ Medicare's payment practices have evolved over the past half-century, but the program's authorizing statute and its several revisions have never linked prices paid for particular tests or treatments to their effects on length or quality of life. ${ }^{157}$

When, in 2004, Medicare officials nevertheless tried to take costs into account by permitting contractors (who administer

fee schedules as based on the service's "relative value," "conversion factor," and "geographic adjustment factor").

156. The term "reasonable" invites interpretations that allow consideration of cost-indeed this term is routinely understood in tort and administrative law to permit, even require, cost-benefit balancing. But the agency that administers Medicare (known as the Health Care Financing Administration (HCFA) until 2001, then the Centers for Medicare and Medicaid Services (CMS) thereafter) has never construed "reasonable" along these lines. To be sure, HCFA and CMS have, since 1989, several times explored the possibility of weighing costs when making coverage decisions: the agency has gone as far as to propose decisionmaking rules that explicitly incorporate cost concerns. Jacqueline Fox, The Hidden Role of Cost: Medicare Decisions, Transparency and Public Trust, 79 U. CIN. L. REV. 1, 15-16 (2010). But the agency has always backed off in the face of strong resistance from stakeholders and Congress, $i d$. at 14, further evidence of the practical impossibility of openly withholding potentially-beneficial care on cost grounds.

157. Originally, Medicare payments to hospitals and physicians were set on a fee-for-service basis, via formulae that took into account individual institutions' costs and prices charged to private payers by local providers. Kathryn M. Langwell \& James P. Hadley, Capitation and the Medicare Program: History, Issues, and Evidence, HeAlth CARE FinANCING REV., Dec. 1986, at 9, 9-10. In 1983, Congress introduced payment to acute-care hospitals via "diagnostic related groupings" (DRGs) - diagnostic categories for which fees were set (after adjustment for local differences in costs). Elizabeth Davis, Diagnostic Related Grouping and How It Works, VERYWELL HEALTH, https://www.verywellhealth .com/drg-101-what-is-a-drg-how-does-it-work-3916755 [https://perma.cc/492D -23T7] (last updated Mar. 20, 2019). Eight years later, Congress introduced the so-called "Resource-Based Relative Value Scale" (RBRVS) for Medicare physicians' fees: this scheme scores physician services based on doctors' training, effort, and other costs rather than therapeutic impact. Congress and CMS have since pursued a series of payment experiments designed to incentivize quality of performance with little to no regard for tests' and treatments' comparative effectiveness. See generally Alan Weil et al., Securing the Future of Value-Based Payment, HEalth AFF. (Apr. 18, 2017), https://www.healthaffairs.org/do/10 .1377/hp20170418.689533/full/ [https://perma.cc/6GCR-RRHQ] (discussing ACA provisions' focus on value rather than volume and the effect on health care system efficiencies). 
health care providers' compensation) to pay for prescribed treatment no more than the price of the "reasonably feasible and medically appropriate" "least costly alternative,"158 they were stymied by stakeholders and the courts. ${ }^{159}$ Health care providers pushed back, charging that the "least costly alternative" policy invited withholding of beneficial care on account of cost. ${ }^{160}$ They had a point: the terms "reasonably feasible" and "medically appropriate" give Medicare contractors discretion to choose, as benchmarks, "least costly alternative(s)" that forgo therapeutic benefit. 161

As provider opposition mounted, the D.C. Circuit Court of Appeals killed this experiment in cost-awareness, ruling that Medicare's separate coverage decision-making and price-setting schemes barred the program from tying payment rates to therapeutic effectiveness. ${ }^{162}$ Once Medicare chose to cover a treatment as "reasonable and necessary," the court held, it was required to set prices based on statutory formulae, without regard for whether the program's administrators "determined that the $e x$ pense of an item or service" was "reasonable or necessary." 163

158. Medicare Program Integrity Manual, CENTERs FOR MEDICARE \& MEDICAID SERVS.(Apr. 25, 2008), http://www.cms.gov/manuals/downloads/ pim83c13.pdf [https://perma.cc/7AC4-42ZG] (identifying section 13.4.A, part of Revision 71, adopted on Apr. 9, 2004).

159. See Hays v. Sebelius, 589 F.3d 1279, 1283 (D.C. Cir. 2009) ("Nothing in the statute authorizes the least costly alternative policy.").

160. See The 'Least Costly Alternative' Approach for Payment of Medicare Part B Drugs, Pew Charitable Trusts (Mar. 2016), https://www.pewtrusts .org/-/media/assets/2016/03/the_least_costly_alternative_approach_for_ payment_of_medicare_part_b_drugs.pdf [https://perma.cc/682A-4ZYZ] (describing critics' characterization of the policy as "inappropriate and unfair").

161. "Reasonable" is often understood in tort and administrative law as shorthand for balancing benefits against costs. Supra text accompanying notes 108-09. Likewise, "feasible" has long been understood in administrative law as permissive of agency policies that weigh costs. E.g., Indus. Union Dep't v. Am. Petroleum Inst., 448 U.S. 607, 637 (1980). And the term "medically appropriate" confers broad license to choose from among alternative clinical practices that reflect varying implicit balances between benefit and cost. BLOCHE, supra note 46 , at 23-29, 105-06.

162. Hays, 589 F.3d at $1281-82$.

163. Id. at 1282 (internal quotations omitted). 


\section{StAKEHOLDERS, ExPECTATIONS, AND LEVERS OF INFLUENCE}

The myriad actors that provide $\$ 3.5$ trillion in health care services and products per year ${ }^{164}$ do business within this cultural, financial, and legal milieu. This environment rewards industry actors for developing and marketing new technologies with little regard for their degree of therapeutic benefit. Doctors, hospitals, and other health care providers, in turn, have powerful incentives to adopt these technologies and to invest in the training, equipment, and bricks and mortar needed to deploy them. The psychology of rescue, the ethical and legal architecture that reflects and reinforces it, and the public and private insurance schemes that finance it lock in these incentives for the long term. This lowers the risk attached to the investments these incentives invite.

Moreover, once industry actors make these investments, they are strongly motivated to protect them. Efforts by health care payers or government regulators to restrain spending on services to which industry actors have made large business commitments are sure to meet fierce resistance. This resistance employs multiple tools: advocacy that exploits the legal doctrines and regimes we've discussed, political messaging that leverages popular outrage over the withholding of life-prolonging care, and marketing that stokes hopes for life-changing therapeutic impact.

164. Sisko et al., supra note 14 (reporting total U.S. medical spending in 2017). 
Trade associations, ${ }^{165}$ corporate advocacy 166 and marketing 167 arms, and "astroturf" consumer groups ${ }^{168}$ funded by industry stakeholders ${ }^{169}$ press the case for coverage of expensive tests and treatments. These actors also reach prescribing and referring physicians directly, through their dominant role in funding continuing medical education (and shaping its content) ${ }^{170}$ and

165. The American Medical Association (AMA) has long been seen as the marquee trade group when it comes to influence on politics, legislation, and regulation in the health sphere, but medical specialty societies are eclipsing its influence. Other powerful influencers include the American Hospital Association, the Federation of American Hospitals (investor-owned hospitals), the Association of Academic Health Centers, the Pharmaceutical Research and Manufacturers of America (PhARMA), and the Medical Device Manufacturers Association (MDMA).

166. Investor-owned and non-profit hospital systems and pharmaceutical and medical-device firms operate their own legislative and regulatory advocacy shops, retain outside lawyers and lobbyists, back political candidates, and otherwise exercise enormous influence on federal and state healthcare policy. Jennifer Liberto, Health Care Lobbying: Political Power Machine, CNNMONEY.COM (Sept. 13, 2009, 6:47 AM), https://money.cnn.com/2009/09/08/news/economy/ health_care_lobbying/?postversion=2009090813 [https://perma.cc/738N-8553].

167. Through image advertising and promotion of products and services (to clinicians and to consumers directly), industry actors exercise large influence on public perceptions, shaping consumers' expectations of particular products and services and of medical technology more generally. Michael S. Wilkes et al., Direct-to-Consumer Prescription Drug Advertising: Trends, Impact, and Implications, 19 HEALTH AFF. 110, 119-20 (2000).

168. "Astroturf" advocacy groups are entities fronted by apparent grassroots activists but created and funded by industry stakeholders, with an eye toward creating the illusion of broad, grassroots support for the stakeholders' positions on issues. HedRICK SMITH, THE POWER GAME: How WASHINGTON WORKS 24546 (1988).

169. Lauren Clason \& Andrew Siddons, Health Industry Reports Lobbying Costs the Size of a Grapefruit-Drugmakers Lead, ROLL CALL (Oct. 23, 2018, 1:53 PM), https://www.rollcall.com/news/policy/health-industry-led-by -drugmakers-report-big-lobbying-costs [https://perma.cc/RE33-XG29].

170. JEROME P. KASSIRER, ON THE TAKE: How MEDICINE's COMPLICITY WITH Big Business CAN ENDANGER Your HEALTH 15-16 (2005). Physicians are captive audiences for $\mathrm{CME}$ - states impose annual CME requirements for continued licensure, medical specialty societies require it for ongoing certification, and many hospitals make it a prerequisite for admitting and operating privileges. See Physician CME State Map, RELIAS MEDIA, https://www.reliasmedia .com/pages/cme-state-map?utm_campaign=featuredsidebar\&utm_medium= web\&utm_source=cmeweb.com [https://perma.cc/8D92-7K38] (last updated June 21, 2019) (detailing license requirements by state). Through vehicles like Medscape (which gives physicians access to a massive selection of free, industryfunded online CME), conference sponsorships, and "gifts" to hospitals and clinics to support presentations, drug and device makers influence the content of 
their financial support for so-called "key opinion leaders"171 (prominent academic and other specialists whose pronouncements influence standards of care). Direct-to-consumer, "ask your doctor" advertising, moreover, mobilizes patients to seek out pricey drugs, devices, and services. ${ }^{172}$ News outlets report uncritically (sometimes prompted by stakeholders' promotional efforts) on the promise of new therapies. ${ }^{173}$ Patients and their families, in turn, pursue them, pressing their doctors for prescriptions and referrals. Physicians, motivated to satisfy their patients, comply, aiding in the establishment of these therapies as standards of care, often before their efficacy has been scientifically established. ${ }^{174}$

These dynamics of influence play out within an environment made favorable by Americans' reverence for technology, the hopes and fears of patients and family members who face dire

CME, both directly and by choosing topics and speakers. AVORN, supra note 130.

171. Pharmaceutical firms, device manufacturers, and other industry actors fund these physicians' research studies, appoint them to paid advisory boards, and retain them as consultants. This process is subtle-outright payments for product endorsements are rare; rather, it relies on the building of relationships and trust over time. See Ashley Wazana, Physicians and the Pharmaceutical Industry: Is a Gift Ever Just a Gift?, 283 J. AM. MED. ASs'N 373, 375-78 (2000) (comparing frequency of physician interactions with pharmaceutical industry representatives and corresponding outcomes).

172. Ram Bala \& Pradeep Bhardwaj, Detailing vs. Direct-to-Consumer Advertising in the Prescription Pharmaceutical Industry, 56 MGMT. SCI. 148, 14849 (2010).

173. See, e.g., Apoorva Mandavilli, A Simple Regimen Can Prevent TB. Why Aren't More People on It?, N.Y. Times (Sept. 23, 2019), https://www.nytimes .com/2019/09/23/health/tuberculosis-prevention.html?\&moduleDetail=section -news-1\&action=click\&contentCollection=Health\&region=Footer\&module= MoreInSection\&version=WhatsNext\&contentID=WhatsNext\&pgtype=Blogs [https://perma.cc/XVK9-WMEG] (reporting on a new drug therapy for tuberculosis).

174. Examples of technology adoption catalyzed by industry promotional efforts, absent good scientific evidence, include CT angiography; see Julie Appleby, The Case of CT Angiography: How Americans View and Embrace New Technology, 27 HEALTH AFF. 1515, 1517 (2008) (reporting on how GE and cardiologists who purchased GE cardiac CT scanners lobbied Congress to press Medicare to broaden its coverage criteria for these scans absent supporting evidence), and estrogen replacement therapy for post-menopausal women to prevent cardiovascular disease. See ELIZABETH SIEGEL WATKINS, THE EsTROGEN Elixir: A History of HoRMONE REPLACEMENT THERAPY IN AMERICA 243 (2007) (discussing estrogen's rise in popularity, which was buoyed by drug manufacturers' efforts). 
medical circumstances, and the trust in physicians that patients sustain, indeed feel more deeply, when they hear bad health news. ${ }^{175}$ Healthcare reformers from across the ideological spectrum have proposed myriad policy fixes. Liberals have focused on limiting corporate influence on medical research and practice, eliminating financial conflicts of interest, ${ }^{176}$ empowering government to stop the spread of low-value services, and protecting patients' autonomy from paternalistic physicians. Conservatives have urged an array of consumer-choice approaches, from offering patients a wide variety of cost-benefit trade-off policies at the health plan sign-up stage ${ }^{177}$ to shifting clinical costs from health insurers to patients (by raising copayments and deductibles). ${ }^{178}$

These solutions fly in the face of the powerful forces we've described. They assume, rather than offer, answers to the Gordian web of challenges we've set out-the psychological and cultural forces, stakeholder expectations, and ethical and legal frameworks that reflect and reinforce our national inability to say "no" to high-cost, low-value care once it becomes available. These challenges stand in the way of adoption of the reforms that liberals and conservatives have urged. For more than a half century, they have stymied medical cost-containment efforts regardless of ideological pedigree. ${ }^{179}$

\section{A Lightning-Round Review of FAiled Cost-Control POLICY}

Prior to the creation of Medicare and Medicaid in 1965, rising health spending wasn't a matter of much interest to federal policymakers. To be sure, critics of these programs objected to burdening taxpayers with their costs, ${ }^{180}$ but future escalation of

175. See KATZ, supra note 59 at 100-01 (contending that patients tend to regress to more childlike, trusting states of mind-and thus experience greater trust in their physicians - when they fear for their health).

176. E.g., Marc A. Rodwin, Conflicts of Interest, Institutional Corruption, and Pharma: An Agenda for Reform, 40 J.L. MED. \& ETHICs 511, 511 (2012).

177. E.g., HAVIGHURST, supra note 98.

178. E.g., ChARLES Silver \& DAVID A. HyMAN, Overcharged: Why AMERICANS PAY TOO MUCH FOR HEALTH CARE 284, 287 (2018).

179. See supra text accompanying notes 158-59.

180. Most famously, in 1961 the actor-turned-political-commentator Ronald Reagan condemned use of tax dollars to pay for medical care for the elderly, disabled, and poor as "socialism." ReaganFoundation, Ronald Reagan Speaks Out on Socialized Medicine-Audio, YouTuBE (July 23, 2009), https://www .youtube.com/watch?v=AYrlDlrLDSQ [https://perma.cc/N5NP-9CTQ]. 
medical spending wasn't this opposition's focus. Leading health economists presumed that physicians' Hippocratic devotion to their patients would guard against excessive spending, ${ }^{181}$ and the programs' drafters gave the medical profession virtual carte blanche to determine clinical need. ${ }^{182}$ But within a few years of these programs' implementation, their soaring costs were arousing Congressional alarm. A 1969 Senate Finance Committee report projected Medicare's fiscal year 1970 price tag at almost double the amount anticipated in $1965 .{ }^{183}$ Comparable projections aren't available for Medicaid, but over the program's first five years, its total cost to federal, state, and local governments jumped by more than $300 \% .{ }^{184}$

\section{Health Planning}

After years of debate over rival regulatory and market-oriented remedies, Congress settled in 1974 on a scheme that sought to control costs by limiting the supply of high-priced clinical services. ${ }^{185}$ It required each state to establish a network of local and statewide bodies-some with stakeholder representatives - to create comprehensive plans for capital investmentplans for numbers of hospital beds and for myriad specialized

181. See, e.g., Kenneth Arrow, Uncertainty and the Welfare Economics of Medical Care, 53 AM. ECON. REV. 941, 947-48 (1963) (analyzing physicians' Hippocratic altruism as a market response to the possibility that patients' medical ignorance could give rise to distrust).

182. Like private insurers, Medicare covered clinical services so long as treating physicians deemed them "necessary," with minimal review of treating doctors' decisions. See supra notes 156-57 and accompanying text.

183. StafF of The S. Comm. ON Fin., 91st Cong., StafF Data RElating to MedicAid-Medicare StUdy 10 (Comm. Print 1969) (noting increase in projected fiscal year 1970 spending from $\$ 2.9$ billion in 1965 to $\$ 5$ billion in 1969).

184. Id. at 2 ("Between 1965 and 1970, total Federal, State, and local costs will have risen from $\$ 1.3$ to $\$ 5.5$ billion.”).

185. See National Health Planning and Resources Development Act of 1974, Pub. L. 93-641, 88 Stat. 2225 (1975) (formerly codified at 42 U.S.C. $§ 300 \mathrm{k}-$ 300n-5) repealed by Pub. L. 99-660, title VII, § 701(a), 100 Stat. 3743, 3799 (1986). The premise behind this approach was that insurance induces sufficient demand to fill available hospital beds, surgical suites, and other high-cost clinical facilities, making regulatory constraints on supply critical to cost containment. See Milton I. Roemer, Bed Supply and Hospital Utilization: A Natural Experiment, 178 J. AM. MED. ASS'N 989, 991-92 (1961) (setting out and testing this premise, which became known as "Roemer's Law"). 
facilities and services. ${ }^{186}$ Proposed new hospitals and other facilities that exceeded these plans could, in theory, not be built; the idea was to cap availability of costly care in the face of insatiable, insurance-fueled demand.

But stakeholders' resistance ensured that this lid on supply would leak freely. The 1974 statutory scheme that engineered it denied health planners the power to shut down existing facilities even when they offered capacity that exceeded planners' prescribed limits. And mechanisms of political influence-from health-care industry representation on local planning bodies to doctors' and hospitals' sway over state officials-eased healthcare providers' way to obtaining state approval (known as a "Certificate of Need" or "CON") for new facilities. ${ }^{187}$ Regulators appointed by or accountable to governors and legislators had little incentive to anger providers by saying no.

Doctors and hospitals, moreover, could and did mobilize public support by warning that refusal to confer Certificates of Need put lives and well-being at risk. ${ }^{188}$ And when regulators withheld approvals, providers often appealed to the courts, ${ }^{189}$ exploiting judges' reluctance to risk adverse health consequences. Protracted litigation and remands to regulators for reconsideration often ensued as judges strained to avoid visibly compromising people's health. In short, the interwoven personal psychology, public expectations, professional ideals, and stakeholder interests that we've described 190 ensured health planning's failure as a remedy for rising costs. Eliminating only care that lacked any therapeutic value (or worse, did more harm than good) wasn't enough to restrain medical spending's explosive growth-growth sustained by insurance-fueled technological advance that too often yielded little therapeutic value. ${ }^{191}$ To suc-

186. See National Health Planning and Resources Development Act $\S \S 1512-12,1522-23$.

187. See id. $\S 1523(\mathrm{a})(4)(\mathrm{A})$.

188. See generally David Mechanie, The Managed Care Backlash: Perceptions and Rhetoric in Health Care Policy and the Potential for Health Care Reform, 79 MILBANK Q. 35, 38-41 (2001) (highlighting various contributing factors to the managed care backlash, including dissatisfied physicians).

189. See, e.g., Nat'l Gerimedical Hosp. \& Gerontology Ctr. v. Blue Cross of Kansas City, 452 U.S. 378, 380-81 (1981).

190. See, e.g., supra Part I.A.

191. See, e.g., supra Part I.B.4. 
ceed, health planners would have had to make compromises between health and other social needs that the surrounding ecology of beliefs and interests disallowed.

\section{Hospital Rate Regulation}

The same was the case for another early regulatory response to rising costs - the capping of hospital rates. By the end of the 1970s, hospital rate regulation had proven effective at slowing the growth of clinical spending. ${ }^{192}$ Not only did it contain inpatient costs (the largest component of U.S. medical spending193); its spillover effects likely included lower spending on physician services. ${ }^{194}$ The several states that adopted it ${ }^{195}$ achieved cost control that Certificate-of-Need regulation didn't match. ${ }^{196}$ Encouraged by this success, the Carter Administration proposed a nationwide hospital rate-setting scheme in 1979.197

But industry resistance kept this regulatory model from spreading. Hospital executives mobilized opposition by warning

192. See Paul L. Joskow, Controlling Hospital Costs: The Role of GOVERNMENT REGULATION 139-68 (1981) (examining the economic effects of government regulation of hospital rates).

193. For the past fifty years, spending on hospital care has comprised between one third and two fifths of U.S. medical costs, more than spending on physician services, pharmaceuticals, or any other clinical sector. See National Health Expenditures by Type of Service and Source of Funds, CMS, https://www .cms.gov/ (follow "Research, Statistics, Data, \& Systems" hyperlink; then follow the "National Health Expenditure Data" hyperlink under the "Statistics, Trends, \& Reports" tab; then follow the "Historical" hyperlink) [https://perma .cc/2LG9-DEQY].

194. See Robert Murray \& Robert Berenson, Urban Inst., Hospital Rate Setting Revisited: Dumb Price Fixing or a SMart Solution to ProVIDER PRICING POWER AND DELIVERY REFORM? 60-61 (2015) ("[S]tudies suggest that spending for physician services was lower in states with rate setting ....").

195. David A. Crozier, State Rate Setting: A Status Report, HEALTH AFF., Summer 1982, at 66 (identifying the seven states with mandatory rate control programs at the time: New York, Connecticut, Maryland, Massachusetts, New Jersey, Washington, and Wisconsin).

196. Joskow, supra note 192, at 76-80 (comparing results from Certificateof-Need and hospital rate regulation).

197. See Jimmy Carter, Hospital Cost Containment Message to the Congress Transmitting Proposed Legislation, AM. Presidency ProjeCt (Mar. 6, 1979), https://www.presidency.ucsb.edu/documents/hospital-cost-containment -message-the-congress-transmitting-proposed-legislation [https://perma.cc/ 688P-LFZ4]. 
that rate setting compromised quality of care. ${ }^{198}$ Physicians reinforced these warnings, arguing that restraints on inpatient rates rendered hospitals less able to build new facilities, acquire state-of-the-art technology, and thereby save lives. 199 President Carter's rate-setting proposal went nowhere, and by 1980 a state-level retreat from hospital rate regulation was well underway. ${ }^{200}$ That these admonitions about health care quality gained enough political traction to roll back rate regulation despite its cost-control success underscores our national resistance to tradeoffs between medicine's benefits and other human needs.

\section{The Market Responds: Managed Care}

Through the 1970s, private health insurers paid doctors and hospitals virtually on demand, without critical review of the medical rationale for tests and treatments. But as support for regulatory responses to rising costs ebbed in the 1980 s, health plans (and employers, who pay for most private coverage) asserted their market power. They declined coverage, at times, for costly services, citing "medical necessity" clauses in their contracts with subscribers. 201 They offered financial rewards to physicians for frugal practice and made compliance with money-saving clinical protocols a precondition for participation in provider networks. ${ }^{202}$ To put market muscle behind these new ways of doing business, they offered patients steep discounts for choosing in-network doctors and hospitals; this, in turn, enabled health

198. See Crozier, supra note 195, at 68-70.

199. House Kills Carter Hospital Cost Control Plan, 35 CQ ALMANAC 512, 513 (1979). The Federation of American Hospitals, the American Hospital Association, and the American Medical Association "suggested the bill would harm health care in the United States by forcing hospitals to curtail services to keep down costs." Id.

200. See John E. McDonough, Tracking the Demise of State Hospital Rate Setting, HeALTH AFF., Jan.-Feb. 1997, at 142, 143-44.

201. See Mark A. Hall \& Gerard F. Anderson, Health Insurers' Assessment of Medical Necessity, 140 U. PA. L. REV. 1637, 1641 (1992) (opining that "previous contract disputes involved treatment at the periphery of traditional medicine with only modest amounts of money at stake" but, with medical necessity clauses, "the stakes are much higher on both sides").

202. See generally Linda J. White \& John Ball, Integrating Practice Guidelines with Financial Incentives, 16 QUALITY REV. BULL. 50, 51-52 (1990) (anticipating that the results of medical effectiveness studies will be used to inform physicians and patients about appropriate medical care and to assist public and private insurers in developing coverage policy). 
plans to reward compliant providers with larger numbers of patients. ${ }^{203}$

By the early 1990s, the insurance industry had evolved a medley of health plan designs that made use of varying mixes of these methods, all the while continuing to promise, via contract, "medically necessary" care. ${ }^{204}$ Federal law favored these designs, which came to be known as "managed care." A 1973 statute supplied subsidies to HMOs that employed these methods, preempted state laws restricting them, and required employers offering health insurance to include an HMO option. ${ }^{205}$ And the Employee Retirement Income Security Act (ERISA) ${ }^{206}$ gave carte blanche to medical-necessity-based coverage denials through its preemption of state tort and contract law. ${ }^{207}$ ERISA preemption barred Americans who obtained coverage via the workplace from suing their health plans for consequential damages; they could sue (in federal court) only for the value of the benefits denied. ${ }^{208}$

Public programs likewise embraced managed care. State Medicaid programs experimented with HMOs in the 1980s, then

203. See generally Peter D. Fox \& Peter R. Kongstvedt, A History of Managed Health Care and Health Insurance in the United States, in THE EssEnTIALs OF MANAGED HEAlth CARE 7 (Peter R. Kongstvedt ed., 5th ed. 2007) (exploring the development of managed health care and coinciding health insurance models in the United States).

204. M. Gregg Bloche, One Step Ahead of the Law: Market Pressures and the Evolution of Managed Care, in The Privatization of Health Care Reform: LEGAL AND REgulatory PERsPeCTIVES 27-33 (M. Gregg Bloche ed., 2003) (noting the agility of the market's response to consumer concerns).

205. Health Maintenance Organization Act of 1973, Pub. L. No. 93-222, 87 Stat. 914 (codified as amended at 42 U.S.C. $\$ \S 300 \mathrm{e}-14$ a (1978)).

206. Employee Retirement Income Security Act of 1974, Pub. L. No. 93-406, 88 Stat. 832 (codified as amended at 29 U.S.C. $\$ \S 1001-461$ (2012)).

207. Metropolitan Life Ins. Co. v. Taylor, 481 U.S. 58, 62 (1985) ("[Plaintiff]'s common law contract and tort claims are pre-empted by ERISA.").

208. Fully-integrated HMOs-firms that provided health insurance and medical services within a single corporate structure-were (and are) not protected by this de facto tort immunity. Lower federal courts construed ERISA to preempt state damage suits against insurers for denial of coverage (since ERISA preempted such damage suits against employee benefit plans) but not suits against fully-integrated HMOs for failure to provide adequate care. See, e.g., Dukes v. U.S. Healthcare, Inc., 57 F.3d 350, 356 (1995) (holding that such a claim against an HMO is beyond the scope of ERISA pre-emption because it "merely attack[s] the quality of the benefits received"). 
moved most of their clients to managed care in the 1990s. 209 Medicare managed care also grew rapidly in the 1990s (though most Medicare beneficiaries stayed with traditional, fee-for-service coverage). 210

For several years, in the mid to late 1990s, U.S. medical costs stabilized as a share of GDP, ${ }^{211}$ due largely to rapid transition from traditional fee-for-service to managed care. HMOs and other aggressively-managed health plans cost less, compared to traditional coverage, though their annual price increases were roughly similar. ${ }^{212}$ But managed care had hidden a core truth. As a unanimous U.S. Supreme Court put it in 2000: "inducement to ration care goes to the very point of any HMO scheme."213 HMOs struck balances, the Court noted, concerning "acceptable medical risk" and "optimum treatment levels"214_balances that sacrificed therapeutic benefit to conserve resources for other purposes. So did other forms of managed care, drawing upon financial inducements, administrative controls, and bargaining power over providers to contain clinical resource use. ${ }^{215}$

Managed health plans didn't admit to doing this. ${ }^{216}$ They hid the reality of rationing behind the euphemism of medical necessity, insisting that they were honoring their contractual commitments to cover all care that met this standard. ${ }^{217}$ For a time, they

209. See Carlos Zarabozo, Milestones in Medicare Managed Care, 22 HeAlthCARE FinANCING REV., Fall 2000, at 61, 64-65 (describing the "fits and starts" of Medicaid programs in the late 1980s and early 1990s).

210. See id. at 61, 65. A variety of legislative and regulatory changes nurtured Medicare managed care's growth, to more than fifteen percent of all Medicare beneficiaries by 1999. $I d$.

211. Sheiner, supra note 12.

212. Zarabozo, supra note 209, at 61-62.

213. Pegram v. Herdrich, 530 U.S. 211, 221 (2000).

214. Id.

215. See Bloche, Invention of Health Law, supra note 40, at 253, 287-98 (elaborating on techniques utilized in attempts to fine-tune health care efficiency); Bloche, Trust and Betrayal, supra note 101, at 935-39, 938 n.94 (discussing the relationship between trust and the creation of unrealistic expectations in consumers and patients).

216. See Robert Pear, The ' $R$ ' Word: Justice Souter Takes on a Health Care Taboo, N.Y. TIMES, June 18, 2000, at WK3 (discussing how the essence of the HMO concept is rationing, even if that is not expressly stated by the plans themselves).

217. See id.; see also Hall \& Anderson, supra note 201, at 1639 n.12, 1640 41, $1640 \mathrm{nn} .13-14$ (listing and elaborating on litigation surrounding the construction of "medical necessity" language in health insurance contracts where 
seemed to pull off health policy's impossible feat-withholding beneficial, even lifesaving care in order to restrain costs (and thereby succeeding where health planners ${ }^{218}$ and hospital rate regulators ${ }^{219}$ failed).

But this time was short. As managed care spread across private insurance markets in the $1990 \mathrm{~s}$, its covert cost-saving practices gained notice and aroused ire. ${ }^{220}$ Many were shocked to learn that ERISA, in most cases, ${ }^{221}$ immunized health plans against liability for the consequences of coverage denied. Congress and many state legislatures advanced "Patients' Bill of Rights" proposals ${ }^{222}$ to limit health plans' discretion to deny coverage and to expand patients' legal remedies. Legislative hearings and investigative journalists spotlighted egregious episodes of harm resulting from care withheld. ${ }^{223}$ Class action suits, employing a potpourri of legal theories, targeted managed care's

insurers maintained that they were honoring their contractual commitments to that language).

218. See supra Part I.D.1.

219. See supra Part I.D.2.

220. See Robert J. Blendon et al., Understanding the Managed Care Backlash, HEALTH AFF., July-Aug. 1998, at 80, 82-85 (studying and then discussing public opinion of managed care and its influencing factors); Alain C. Enthoven \& Sara J. Singer, The Managed Care Backlash and the Task Force in California, HEALTH AFF., July-Aug. 1998, at 90, 96-97 (discussing contributions to the backlash towards managed care by various groups).

221. In the 1990s (as is the case today), more than 150 million Americans received health insurance via the workplace and were thus precluded by ERISA preemption from seeking state tort or contract damages for the consequences of coverage denials. See supra, text accompanying notes 206-08 (discussing ERISA-controlled health benefits plans). See generally Cynthia B. Sullivan \& Thomas Rice, Datawatch: The Health Insurance Picture In 1990, HEALTH AFF., Summer 1991, at 104, 104-05 (listing and discussing data on employer-provided health insurance in 1990); Dan Managan, Number of People with Health Insurance via Jobs Remained Steady with Obamacare, CNBC (July 13, 2016), https://www.cnbc.com/2016/07/13/number-of-people-with-health-insurance-via -jobs-remained-steady-with-obamacare.html [https://perma.cc/LY5L-2KM9] ("There are an estimated 155 million people under age 65 covered by [employersponsored insurance] plans.").

222. See M.J. Binette, Patients'Bill of Rights: Legislative Cure-All or Prescription for Disaster?, 81 N.C. L. REV. 653, 673-88 (2003) (discussing States' efforts to pass such bills); Faith McLellan, U.S. House Passes Patients' Bill of Rights, 358 LANCET 480 (2001) (discussing the bills advanced in Congress).

223. See, e.g., Stuart Auerbach, Managed Care Backlash, WASH. PosT: HEALTH, June 25, 1996, at 12. 
cost-cutting practices. ${ }^{224}$ And in TV dramas, ${ }^{225}$ films, ${ }^{226}$ and latenight comedy, ${ }^{227}$ health insurers became villains and punchlines.

Efforts to enact a federal "Patients' Bill of Rights" failed. ${ }^{228}$ Class action suits against managed health plans were thrown out before they could reach the discovery stage. ${ }^{229}$ Employmentbased health insurance retained its ERISA immunity from damage suits. ${ }^{230}$ But the reputational damage had been done. Consumers shied away from the most restrictive health plans. ${ }^{231}$ Employers, in the late 1990s, were less inclined to offer them,

224. See M. Gregg Bloche \& David M. Studdert, A Quiet Revolution: Law as an Agent of Health System Change, HeALTH AFF., Mar.-Apr. 2004, at 29, 3637 .

225. See, e.g., Jill Wechsler, HMOs Go Hollywood, MANAGED HEALTHCARE EXECUTIVE (Aug. 1, 2002), http://managedhealthcareexecutive.modernmedicine .com/managed-healthcare-executive/content/hmos-go-hollywood (reporting on the leading managed care trade association's retaining of a Hollywood agent to push back against unfavorable portrayals of the industry in popular television dramas).

226. E.g., As GoOD AS IT GETS (TriStar Pictures 1997) (health insurer refuses to cover costly asthma care for the son of Helen Hunt's character, a struggling waitress); THE RAINMAKER (Constellation Entertainment 1997) (Matt Damon and Danny DeVito are lawyers who defeat a villainous insurance company in court after it refuses to cover treatment for a child with leukemia).

227. E.g., The Tonight Show with Jay Leno: Episode \#8.252 (NBC television broadcast Aug. 23, 2000) (making fun of HMOs for supposedly requiring patients consult with the doctor in a group rather than individually in an effort to cut costs).

228. Many states enacted "Patients' Bill of Rights" laws, offering widely-varying protections, albeit limited by ERISA preemption. See generally Binette, supra note 222, at 673-88 (2003) (discussing Texas, Georgia, and North Carolina, specifically). And by August 2, 2001, both houses of Congress had passed versions of a federal "Patients' Bill of Rights," triggering formation of a conference committee. McLellan, supra note 222, at 480 (2001) (discussing the differences between the version that passed the House and the version that passed the Senate). A month later, the 9/11 terror attacks transformed Congress's agenda, and the conference-committee process never progressed.

229. Bloche \& Studdert, supra note 224, at 29.

230. See Aetna Health Inc. v. Davila, 542 U.S. 200 (2004) (upholding a sweeping view of ERISA preemption that prevents states from enacting statutes making employment-based health insurance liable in tort for coverage denials).

231. See Bloche \& Studdert, supra note 224, at 37 (discussing consumer anxiety with managed care plans); Jerome Dugan, Trends in Managed Care Cost Containment: An Analysis of the Managed Care Backlash, 24 HEALTH ECON. 1604, 1606 (2015) (compiling and discussing data that show rapid disenrollment from managed care plans). 
especially as the U.S. economy neared full employment, heightening competition for workers. ${ }^{232}$ Capital markets, as well, signaled their concerns, pushing share prices down in response to developments that sullied managed care's image. ${ }^{233}$ Rather than responding with contractual transparency about rationing they'd previously kept covert, health plans backed away from aggressive managed-care practices, ${ }^{234}$ aware that candor about forgoing therapeutic benefit to save money was no recipe for preserving market share.

The predictable result was that, after 2000, medical spending again began to rise more rapidly than GDP. ${ }^{235}$ Like health planning and hospital rate regulation, managed care's methods could have contained medical spending by forcing trade-offs between therapeutic benefit and other social needs. But this would have required patients and their loved ones to accept such tradeoffs-and to tolerate their physicians' leave-taking from the Hippocratic ideal of undivided commitment to patients' wellbeing. And it would have required the medical profession to embrace this sharp break with long-standing values.

Such a radical departure from social expectations, sick people's emotional needs, and professional ideals was not in the cards. Managed care's leaders understood this. So, they tried to keep rationing covert-hidden behind health insurers' traditional contractual promise of "medically necessary" care. ${ }^{236}$ But America's entrepreneurs of revelation-investigative journalists, plaintiffs' lawyers, consumer activists, academics, and crusading legislators-exposed the reality of trade-offs between clinical benefits and costs. ${ }^{237}$ Even the U.S. Supreme Court got

232. See Bloche \& Studdert, supra note 224, at 38 (noting "increased pressure on health plans to move away from aggressive cost management").

233. See id. at 37-38.

234. See Bloche, supra note 204 (noting the agility of the market's response to consumer concerns); Dugan, supra note 231, at 1604-05 (discussing organizational awareness of backlash against managed care).

235. Sheiner, supra note 12.

236. See Zarabozo, supra note 209, at 61-62; see also Hall \& Anderson, supra note 201 , at 1640-41 (identifying instances where managed care insurers' commitment to the "medically necessary" language in their policies lead to litigation).

237. See supra Part I.C. 
into the act, invoking health care's "R-word" 238 seven times 239 (in its 2000 opinion rejecting an ERISA challenge to rewards to doctors for withholding services ${ }^{240}$ ) to drive home the message that HMOs reduce spending by rationing care. Keeping this rationing on the down-low was doomed to fail.

\section{Top-Down Caps on Medical Spending}

A government or private entity can control medical spending by keeping to budget ceilings for hospitals, clinics, or geographic regions. Germany, Canada, and the United Kingdom are among the nations that set such ceilings. ${ }^{241}$ Countries can do so under both public and private health systems: under public schemes, governments allocate pre-set levels of funding, while under private systems, regulators set spending limits. ${ }^{242}$ Canadian provinces, for example, set global health-care budgets based on the funds they receive from Canada's federal government, supplemented by provincial taxes; within these constraints, provinces then negotiate payments to providers. ${ }^{243}$ President Clinton's failed health reform proposal featured a ceiling for most private medical spending: caps on insurance premiums were built into the proposal as a "backstop," in case (as many expected) competition between health plans failed to keep premiums below legislated limits. ${ }^{244}$

Control of spending through top-down caps is simple in theory. In practice, it runs afoul of the politics that beset any scheme

238. See generally Pear, supra note 216 ("Rationing is central to the very idea of H.M.O.s.").

239. Pegram v. Herdrich, 530 U.S. 211, 220-21, 231 (2000) (using "ration" and "rationing" seven times).

240. See id. at 235 (holding that ERISA's fiduciary duty provisions permit employment-based health plans to offer doctors financial incentives to practice inexpensively).

241. See Xingzhu Liu, Policy Tools for Allocative Efficiency of HEALTH SERVICES 35 (2003).

242. See generally The Commonwealth Fund, International Profiles OF HEALTH CARE SYSTEMS 12-15, 19-22, 28-31 (2010), http://www

.commonwealthfund.org/ /media/Files/Publications/Fund\%20Report/2010/Jun/ 1417_Squires_Intl_Profiles_622.pdf [https://perma.cc/5XJN-PE7R] (discussing the Canadian, German, and English health care systems, in turn).

243. Id. at $12-15$.

244. Walter A. Zelman, The Rationale Behind the Clinton Health Reform Plan, HEALTH AFF., Spring 1994, at 9, 21-23 (discussing a "backstop" premium cap mechanism). 
of allocation within such caps. Ferocious struggles over fixed resources are an ongoing feature of Britain's National Health Service and other public systems of health care provision. ${ }^{245}$ Acrimony over fees is a pervasive feature of schemes in which a single entity, public or private, constrained by a cap, pays private providers. Claims that caps are too restrictive to cover needed, even lifesaving care are commonplace. ${ }^{246}$ So are the scandals that ensue when clinical caregivers elide gaps between constrained resources and public expectations by rationing covertly or resorting to disinformation ${ }^{247}$ about the care they provide.

The Clinton health reform plan's premium caps became a political target for critics, who gained traction with voters by charging that rationing would result. 248 The ACA's Medicare caps made it into law, only to be repealed in 2018 before they were triggered. ${ }^{249}$ Foes characterized these ceilings as a rationing scheme and called the agency designed to implement them a "rationing board."250 Pitted against public expectations, professional norms, and stakeholders' political influence, spending ceilings have proven unsustainable in practice. ${ }^{251}$

245. E.g., Zara Aziz, The NHS No Longer Has the Resources to Care for Our Sick Population, GUARDIAN, (Jan. 17, 2017), https://www.theguardian.com/ society/2017/jan/17/nhs-no-longer-resources-care-for-sick-population [https:// perma.cc/4PSR-V6J6].

246. E.g., id.

247. See M. Gregg Bloche, Scandal as a Sentinel Event-Recognizing Hidden Cost-Quality Trade-offs, 374 NEW ENG. J. MED. 1001, 1001-03 (2016) (analyzing similar dishonesty within the British National Health Service and the U.S. Department of Veterans Affairs).

248. E.g., Robert Moffit, A Guide to the Clinton Health Plan, Heritage FOUND.: TALKING POINTS 3 (1993) https://www.heritage.org/health-care-reform/ report/guide-the-clinton-health-plan [https://perma.cc/2MCS-5AFB] (criticizing the Clinton health reform plan for necessitating the rationing of medical services).

249. See supra text accompanying notes 151-52.

250. Killing ObamaCare’s Rationing Board, WALL ST. J. (July 1, 2015), https://www.wsj.com/articles/killing-obamacares-rationing-board -1435790411 [https://perma.cc/FN9Z-C92W].

251. Even in countries that set global budgets for most medical spending (e.g., Canada, the United Kingdom, and Germany), these influences have pushed costs upward as percentages of GDP. Per capita spending on medicine remains lower in every other industrialized country than it is in the U.S., but annual rates of increase have been roughly comparable. See ORG. FOR ECON. CoOperation \& DeV., Health AT A Glance 2017, at 133 fig.7.2 (2017), https://www.oecd-ilibrary.org/docserver/health_glance-2017-44-en.pdf?expires 


\section{BEYOND FUTILITY: AN EMERGENT STRATEGY}

Fifty years of failure have shown the unworkability of clinical cost-control strategies that require the withholding of potentially beneficial care. Even the appearance or hope of therapeutic benefit, absent a scientific showing of efficacy, makes it impossible to say "no" to already-established tests and treatments without provoking fierce backlash. Health care policy and law have failed to come to terms with this.

We therefore urge a sharply different approach. Rather than trying to roll back use of existing clinical approaches, we aim to bend the arc of future technology development, toward breakthrough and other high-value treatments and away from the minimal therapeutic improvements that our current system indiscriminately rewards.

\section{A. Quantum Leaps V. "Half-Way Technologies"}

Our rationale rests on medical technology's emergent logic. ${ }^{252}$ Therapies not yet available, even envisioned, don't give rise to vested expectations. Investors, developers, and doctors and hospitals haven't yet made large human and financial capital commitments. Patients and their loved ones aren't outraged by inability to access technologies that don't exist. Clinical ethics don't demand their provision. Preventing the future development of high-cost, low-benefit tests and treatments is thus achievable, whereas wholesale reduction in use of today's pricey, low-yield technologies is out of reach.

To this end, we urge the reshaping of incentives for technology development down the line, so as to reward advances in proportion to their therapeutic impact. Doing so won't substantially cut current medical spending since it does nothing to discourage use of extant tests and treatments. But it would extract greater value from future health spending as technologies emerge, since reward for value would play a larger role in their emergence.

=1566658625\&id=id\&accname=guest\&checksum=AFB444AD6DB723B8 F94562EF5162FD3E [https://perma.cc/F5QA-74RM] (comparing OECD countries' inflation-adjusted average annual rates of growth in per capita health spending for 2003-09 and 2009-16; reporting that the U.S. average annual rate of growth was lower than the OECD average (2.5\% compared to $3.6 \%$ ) for 2003 09 and slightly higher (2.1\% compared to 1.4\%) for 2009-16).

252. See generally M. Gregg Bloche, The Emergent Logic of Health Law, 82 S. CAL. L. REV. 389, 423-28 (2009). 
More than this, scaling economic rewards to therapeutic impact would likely slow health spending's long-term growth. Large therapeutic leaps forward typically arise from breakthroughs in biological understanding-breakthroughs that open the way to elegant clinical interventions. ${ }^{253}$ Such interventions are, in relative terms, simple to administer, decisive, and therefore cheap. ${ }^{254}$ They interact in sophisticated ways with biological systems to set them right. ${ }^{255}$

By contrast, the highest-cost clinical measures tend to be, at once, sophisticated from an engineering perspective and crude in their biological action. ${ }^{256}$ They are "half-way technologies," as the physician and philosopher of medicine Lewis Thomas called them ${ }^{257}$ - substitutes, not fixes, for physiology gone awry. They employ costly personnel to run complex equipment-often for extended periods, since they do little to put our biology back on track. ${ }^{258}$

Compare the antibiotic revolution, for example, to the technology in an intensive care unit. The discovery that substances found in nature could stop bacterial growth by blocking key chemical reactions enabled decisive action to cure dreaded diseases. ${ }^{259}$ But ICU life-support systems are poor substitutes for

253. Cf. Arturo Casadevall \& Ferric C. Fang, Elegant Science, MBIo, https:// mbio.asm.org/content/mbio/9/1/e00043-18.full.pdf [https://perma.cc/NA79

-WMFT] (arguing that biological discoveries can be "elegant" and describing the experiment that lead to the discovery that each new strand of DNA is built upon a previously existing strand as the "most beautiful experiment in biology").

254. To be sure, providers and others may price breakthrough interventions aggressively, as has happened in recent years with some breakthrough pharmaceuticals. Our point here is that the actual costs of provision for breakthrough interventions tend to be low by comparison to treatments that employ sophisticated engineering, software, and the personnel these require. See generally infra note 283 and accompanying text (discussing the research and development costs of new pharmaceutical drugs).

255. BLOCHE, supra note 46 , at 56 .

256. Lewis Thomas, On the Science and Technology of Medicine, in DoING BetTer AND FEeling Worse: HeAlth In THE United STATES 35, 37-38 (1977) (discussing how technology has advanced to provide better diagnoses but is "not yet sufficient to permit either the prevention or outright cure" of the diagnosed diseases).

257. Id.

258. BLOCHE, supra note 46 , at 56 .

259. See, e.g., Robert Gaynes, The Discovery of Penicillin-New Insights After More than 75 Years of Clinical Use, 23 EMERGING INFECTIOUS DISEASES 849, 849-50 (2017) (discussing the discovery of penicillin and labeling it as an event that "changed the course of medicine"). 
normal biological functioning. Or, consider the Nobel-Prize-winning research that revealed the pathways of lipid metabolism, opening the way for pharmaceutical intervention to stop the growth of artery-clogging plaques. 260 The "statin" drugs emerged from this science. ${ }^{261}$ They're remarkably cheap by comparison with the technology-intensive, biologically primitive measures undertaken in cardiac care units.

Shifting clinical innovators' calculus of risk and benefit toward higher-value advances will push innovators toward investment in biological breakthroughs and away from the "half-way technologies" that are disproportionately responsible for rising costs. Over time, we project, the distribution of innovation will shift, from the latter toward the former, as changing rewards are felt. And if this happens, growth in health spending will gradually diminish, toward rates more in line with growth throughout the rest of our economy.

To be sure, some quantum biological leaps yield pricey therapies. A current, high-profile example is curative medication for hepatitis C, a viral infection that kills 400,000 each year. ${ }^{262}$ Prices for a successful course of treatment approach $\$ 100,000.263$ But actual production costs for this course of treatment have been estimated at a few hundred dollars or less. ${ }^{264}$ The five-hundred-fold or greater disconnect between production cost and price stems from industry's strategic calculus about the charges health insurers will bear. ${ }^{265}$ Cure, moreover, averts the costs of

260. See Michael S. Brown \& Joseph L. Goldstein, Familial Hypercholesterolemia: Defective Binding of Lipoproteins to Cultured Fibroblasts Associated with Impaired Regulation of 3-Hydroxy-3-Methylglutaryl Coenzyme A Reductase Activity, 71 Proc. NAT. ACAD. SCI. U.S. AM. 788 (1974).

261. BLOCHE, supra note 46 , at 56 .

262. World HeAlth ORG., Global Hepatitis Report 2017, at 16 (2017), http://apps.who.int/iris/bitstream/handle/10665/255016/9789241565455-eng .pdf;jsessionid=D70D44B77FE817C97AA96F91B5DF6CCE? sequence=1 [https://perma.cc/97V7-XJ4P].

263. Sy Mukherjee, Hepatitis C Drugs Can Cost $\$ 84,000$. This New One May Be Just As Good-But Cost \$300, ForTUNE (Apr. 12, 2018), http://fortune.com/ 2018/04/12/hepatitis-c-cure-300-dollars/ [https://perma.cc/6T3W-XKGY].

264. See Andrew Hillet al., Minimum Costs for Producing Hepatitis C DirectActing Antivirals for Use in Large-Scale Treatment Access Programs in Developing Countries, 58 CliniCAL INFECTIOUs DisEASEs 928, 930-33 (2014) (estimating production costs for various antivirals).

265. See U.S. S. Comm. ON Fin., The Price of Sovaldi AND ITS IMPACT ON The U.S. Health Care System 29-78 (Comm. Print 2015) (discussing how the price of Sovaldi was determined). 
half-way technologies for the management of liver failure and cancer, ${ }^{266}$ as well as the exorbitant costs of liver transplantation $^{267}$ and the discomfort, debilitation, and productivity losses associated with infection. Curative antiviral medication, in short, almost certainly costs less than allowing infection to linger.

Development of a cure for hepatitis C, often cited as a cautionary tale about the cost of clinical breakthroughs, thus illustrates our claim about the cost-saving potential of biological leaps forward. In general, physiological "fixes" that solve serious health problems are cheaper than ongoing, technology-intensive (and thus labor and capital intensive) approaches to managing them. ${ }^{268}$

There's a dismal caveat here: the biomedical advance that enables decisive treatment for a life-threatening disease opens the way for future illnesses that death would have forestalled.

266. The natural progression of untreated hepatitis C is highly uncertain. See Douglas L. Nguyen \& Ke-Qin Hu, Clinical Monitoring of Chronic Hepatitis C Based on Its Natural History and Therapy, 19 ENDOCRINE PRACTICE 292, 293-94 (2013). But it is believed that $75 \%$ to $85 \%$ of initially-infected patients develop chronic infection and that, of these, up to $30 \%$ progress to cirrhosis (irreversible scarring with varying degrees of liver failure). NEAL MEHTA ET AL., Cleveland Clinic CEnTER For Continuing EduCATion: Hepatitis C (2017), http://www.clevelandclinicmeded.com/medicalpubs/diseasemanagement/ hepatology/hepatitis-c/ [https://perma.cc/696D-FS56]. Among chronically-infected patients, the risk of liver cancer is believed to be three to ten percent per year. $I d$.

267. The average charge for liver transplantation in the U.S. in 2017 was $\$ 812,500$, according to a widely-respected employee benefits consulting firm. T. ScotT Bentley \& Steven J. Phillips, Milliman Research Report: 2017 U.S. ORGAN AND Tissue TRANSPLANT Cost Estimates AND Discussion 3, tbl.1 (2017), http://us.milliman.com/uploadedFiles/insight/2017/2017-Transplant -Report.pdf [https://perma.cc/SWM2-CPGG]. Health insurers typically negotiate deep discounts from posted charges, but this average provides an order-ofmagnitude estimate of cost.

268. $C f$. BUTtorfF ET AL., RAND CoRP., MUltiPle CHRONIC CONDITIONS IN THE UNITED STATES 13-17 (2017), https://www.rand.org/content/dam/rand/ pubs/tools/TL200/TL221/RAND_TL221.pdf [https://perma.cc/2XQR-XNTA]

("Americans with five or more chronic conditions make up 12 percent of the population but account for 41 percent of total health care spending."); National Health Expenditures by Type of Service and Source of Funds, CMS, https:// www.cms.gov/ (follow "Research, Statistics, Data, \& Systems" hyperlink; then follow the "National Health Expenditure Data" hyperlink under the "Statistics, Trends, \& Reports" tab; then follow the "Historical" hyperlink) [https:// perma.cc/2LG9-DEQY]. 
Like many preventive tests and treatments, ${ }^{269}$ curative therapies for life-shortening diseases increase medical spending over the long term by extending longevity toward health care's "ragged edge"270 — a realm of debility that lies at the limits of medicine's capacity to cope. This is where spending soars, as we deploy half-way technologies in dire circumstances, often to minimal effect. ${ }^{271}$

On the other hand, the long-term shift we envision in the climate of reward for innovation will, over time, nudge even ragged-edge medicine toward higher-value technologies. We'll never come close to realizing the therapeutic aim envisioned by nineteenth century physician Oliver Wendell Holmes - the "one hoss shay" that functions flawlessly for 100 years, then suddenly fails completely. ${ }^{272}$ But diminished pursuit of technological change that yields low value at great cost on the ragged edge should moderate the burden of caring for those of us who reach it.

Some growth in costs will be inevitable as medicine pushes toward the ragged edge. But growth that delivers commensurate value by adding to people's productive and satisfying years isn't a social or policy problem, any more than is rising spending on information technology ${ }^{273}$ or renewable energy. ${ }^{274}$ The aim of medical cost control policy shouldn't be some arbitrary spending ceiling, but, rather, clinical costs and practices that produce value in line with the rest of our economy.

\section{B. SCALING ECONOMIC REWARD TO THERAPEUTIC IMPACT}

Two incentive systems shape the landscape of rewards for development of new medical technologies: (1) payment schemes for health care providers (including drug and device makers),

269. See M. Gregg Bloche, An Ounce of Prevention?, AM. Prospect (Jan. 6, 2009), http://prospect.org/article/ounce-prevention-0 [https://perma.cc/X4HS

-ZAR9] (explaining how preventative medicine can actually increase medical spending).

270. Daniel Callahan, What Kind of Life? The Limits of Medical ProGRESS 63-68 (1995).

271. Thomas, supra note 256.

272. See Oliver Wendell Holmes, The Autocrat of the Breakfast-Table, 2 ATLANTIC MONTHLY 496-97 (1858) (collecting various essays, as well as the poem The Deacon's Masterpiece: or the Wonderful 'One-Hoss-Shay').

273. See supra text accompanying notes 35-36.

274. See Brad Plumer, Clean Energy Is Surging, but Not Fast Enough To Solve Global Warming, N.Y. TIMES (Nov. 12, 2018), https://www.nytimes.com/ 2018/11/12/climate/global-energy-forecast.html [https://perma.cc/YE4T-B9TT]. 
and (2) market exclusivity rules, including intellectual property protections. They are of varying relative import for different tests and treatments: market exclusivity rules, for example, are minimal influences on the invention of most surgical procedures $^{275}$ but central in drug development. To transform the landscape of rewards for technology development, large changes in both provider payment and market exclusivity will be essential.

\section{Toward Dynamic Value-Based Payment}

Calls to tie provider payment to clinical value have become high fashion in health policy over the past decade. But emerging "value-based payment" schemes ${ }^{276}$ don't target future technology development. Rather, they reward doctors and hospitals with shares from the savings insurers reap when providers practice cheaply, so long as providers meet quality and consumer-satisfaction benchmarks. ${ }^{277}$ The quality benchmarks these schemes employ reflect reigning standards of care, ${ }^{278}$ not relative therapeutic impact. They can be revised from time to time to take account of changing practice norms, but they're not designed to favor large leaps forward over low-benefit advances. Nor do these benchmarks cover more than a small fraction of the services doctors and hospitals provide. Today's "value-based payment" thus incentivizes providers to stint on care without much regard for therapeutic impact. 279 Moreover, it does nothing to channel tech-

275. Associations of medical professionals have almost always taken the position that patent protection for surgical procedures is unethical, and surgeons have rarely sought it. Moreover, while surgical procedures are patentable, federal law bars enforcement of such a patent against medical practitioners who infringe the patent while treating patients. See 35 U.S.C. § 287(c) (2012).

276. Bobbi Brown \& Jared Crapo, The Key to Transitioning from Fee-forService to Value-Based Reimbursement, HEALTh CATAlYST 1 (July 28, 2014), https:/www.healthcatalyst.com/insights/hospital-transitioning-fee-for-service -value-based-reimbursements [https://perma.cc/25P6-B5X6].

277. Id. at 3 (describing the flow of money in a value-based payment system). 278. See Thomas H. Lee \& Laura S. Kaiser, Turning Value-Based Health Care into a Real Business Model, New Eng. J. MED. CATAlyst 2-4 (Oct. 24, 2016), https://catalyst.nejm.org/turning-value-based-health-care-into-a-real -business-model/ [https://perma.cc/P9K9-HQL7] ("[P]ayers are increasingly basing reimbursements on the quality of care provided ....").

279. Today's "value-based payment" is thus little different from the bonuses and penalties insurers employed in the 1990s to press doctors to stint on care with minimal regard for therapeutic consequences. Market and legal backlash against these incentives rendered them unsustainable. See Bloche, supra note 
nology development away from costly, "half-way" measures, toward diagnostic and therapeutic breakthroughs.

To transform provider payment into a tool for changing the trajectory of technological change, reconceiving value-based payment is essential. Rather than rewarding providers for stinting on care today or for adhering to quality benchmarks based only on current clinical standards, value-based payment should become dynamic - scaled to evolving understandings of therapeutic benefit. Ideally, scaling of rewards to results should be introduced for all tests and treatments, but stakeholders' settled expectations are a formidable obstacle to cutting payment for current, low-benefit care. So as a practical matter, we urge focus on clinical approaches that are yet-to-emerge. This elides the problem of vested expectations while targeting technology's future trajectory.

A dynamic system of value-based payment would continually adjust payment rates to take account of the latest evidence of therapeutic efficacy. Fees could be assigned to new tests and treatments based on the evidence that enables their incorporation into clinical practice; these fees could then be adjusted periodically, perhaps annually, as new data accrues. A model for this approach is "Coverage with Evidence Development" (CED), introduced by Medicare in $2005^{280}$ to strike a balance between speedy adoption of promising technologies and avoidance of waste. Under CED, Medicare conditions coverage of new clinical approaches on continued collection of outcomes data, with an eye toward refining coverage criteria as evidence emerges. ${ }^{281}$ Current law prohibits tying Medicare payment rates to measures of efficacy after coverage is conferred;282 we urge that such linkage be required for new tests and treatments. Initially-favorable coverage decisions would then be accompanied by starter rate schedules, to be revised as clinical-outcomes data accumulates.

The way forward toward this approach to payment is now open as never before. Advances in information technology have

204, at 22-48 (discussing market backlash against such bonuses and penalties in the 1990s).

280. Sean R. Tunis \& Steven D. Pearson, Coverage Options for Promising Technologies: Medicare's 'Coverage with Evidence Development,' 25 HEALTH AFF. 1218, 1218-19 (2006).

281. See id.

282. Supra text accompanying notes 156-63. 
revolutionized possibilities for tracking clinical outcomes and patient preferences, then formulating measures of value based upon them. Below, we offer a blueprint for doing so and thereby enabling value-based payment. But first, we turn to the case for transforming the law of market exclusivity in the health sphere into a means for tying economic reward to therapeutic benefit.

\section{Toward Dynamic Patent Protection}

Patents are designed to incentivize innovation by solving a public goods problem. It often takes substantial time, money, and effort to invent or discover a new way of doing things, then develop it into a commercially-viable product or service. This is especially so for medical technologies. ${ }^{283}$ Without patents, prospective competitors could free-ride, profiting at innovators' expense, by incorporating others' inventions and discoveries into their own products and services after these innovations become public knowledge. To the extent that innovators foresee their creations will be copied and rendered less lucrative, they will forego research and development that might yield socially beneficial products and services.

Intellectual property law aims to compensate for this market failure. It gives a patent recipient the right to exclude others from making, using, selling, or importing the patented product or process. ${ }^{284}$ It thus prevents copiers from free-riding on an innovator's efforts; a would-be copier must obtain a license from the innovator (typically for a price) to make use of the patentprotected idea. ${ }^{285}$ A patent thereby empowers the innovator to try to monopolize the return on her creation, encouraging socially-desirable $R \& D$ that the recipient would otherwise forgo.

Here, intellectual property law makes a critical assumption-that purchasers' willingness to pay for a patent-protected innovation is an appropriate measure of the innovation's social value. Where this is the case, we can rely on patent holders and purchasers to settle on prices that yield optimal social benefit (or

283. See generally Joseph A. DiMasi et al., Innovation in the Pharmaceutical Industry: New Estimates of R\&D Costs, 47 J. HEALTH ECON. 20 (2016) (detailing the research and development costs of several pharmaceuticals).

284. See 35 U.S.C. $\S 271$.

285. Id. 
a reasonable approximation thereof). For most products, ${ }^{286}$ willingness-to-pay works reasonably well: we pay for them out-ofpocket, and social consensus accepts our decisions to do so (or not) as measures of value.

This rationale, though, breaks down for most medical spending. Third-party payment, consumer ignorance about clinical effectiveness, and expectations of rescue, encouraged by stakeholders and supported by ethical tradition, ${ }^{287}$ combine to produce pricing and purchasing behavior out of line with medical technologies' therapeutic value. Willingness-to-pay for patent-protected medical technologies is thus a poor measure of their social value, ${ }^{288}$ especially for rescue-oriented tests and treatments covered by insurance. To the extent that sale of a drug or device reaps rewards that exceed its therapeutic value, patent protection delivers a windfall that incentivizes waste. ${ }^{289}$

In theory, the dynamic value-based payment strategy we urge above ${ }^{290}$ could adjust the pricing of patent-protected drugs and devices (and their associated clinical services) to approximate therapeutic benefit, rendering sales revenue into a goodenough metric of social value. In practice, though, such pricing adjustment stands no small chance of falling short: political influence, administrative lag times, and legal challenges are among the potential confounders. So we propose to further incentivize drug and device firms to pursue higher-value R\&D portfolios by moving to a value-based patent system-one whereby an innovator receives patent protection proportionate to the social benefit its invention delivers.

This constitutes a sharp break with the established norm of one-size-fits-all intellectual property protection. But it recognizes that markets for medical care are unique in the degree to which purchasing decisions are disconnected from goods' and

286. Supra text accompanying note 37 .

287. Supra text accompanying notes 37-43.

288. For medical technologies, one can reasonably equate therapeutic and social value, since externalities are small. (We recognize, though, that they are not negligible: both production and waste disposal can inflict environmental harms, and keeping people alive in states of severely-diminished functioning can impose emotional and financial costs on family, friends, and other third parties.).

289. A classic example is the proliferation of "me-too" drugs that offer no marginal therapeutic benefit. See supra text accompanying notes 88-92.

290. Supra text accompanying notes 277-91. 
services' social value. And it adjusts for this reality by varying patent terms based on therapeutic outcome so as to discourage investment in tiny marginal advances and to promote $R \& D$ that aims for clinical breakthroughs. Tying patent terms to medical outcomes would realign intellectual property law in the health sphere with its intended goal: incentivizing socially beneficial innovation. ${ }^{291}$

Medical information technology's new capacity to track myriad clinical outcomes and to value diagnostic and therapeutic measures accordingly makes this transformation feasible. It will, to be sure, add uncertainty to patent holders' business calculus. But this uncertainty reflects clinical and economic reality-the impossibility of knowing in advance how human biology will respond to a new intervention's various uses. To lock down patent terms at the start despite this biological uncertainty would be to make patent law into a waste-inducing insurance scheme, free to drug and device makers and paid for by consumers via patent holders' monopoly pricing.

Had a value-based patent system operated in recent years, many of today's entrenched, minimally-beneficial tests and treatments would not have been developed. Stakeholders' settled expectations are a daunting obstacle to removing these marginal measures from medicine's toolkit. But scaling patent terms to therapeutic results for innovations yet-to-emerge can dissuade firms from developing tomorrow's marginal measures and encourage them to instead aspire higher.

Some might blanch at the thought of departing from a uniform scheme of patent protection for all industries. But intellectual property law is a means to an end. It presumes the value of innovation as assayed by market demand, then wields the crude tool of state-sanctioned monopoly to correct for the large disincentive to innovate that free-riding introduces. Where, as in medical care, market forces drive innovation in hugely wasteful directions, this crude tool needs some redesign to pursue the productivity for which it was intended.

291. See Alan Devlin \& Neel U. Sukhatme, Self-Realizing Inventions and the Utilitarian Foundation of Patent Law, 51 WM. \& MARY L. REV. 897, 914 (2009). 


\section{BENDING THE ARC OF INNOVATION: VALUE-BASED PAYMENT AND VALUE-BASED PATENTS}

Law can't by itself bend the arc of medical innovation. But legal change can go far toward aligning innovators' economic incentives with therapeutic impact. In this Part, we offer a blueprint for reform designed to fulfill the vision of value-based reward that we set out in Part II. We intend this blueprint as both a demonstration of feasibility and a starting point for discussion. A variety of reform designs aimed at achieving this vision are possible: we make no claim to have devised the only options. We recognize, also, that further details must be fleshed out to turn our blueprint into reality.

We begin with an approach to valuing medical advancesan approach that takes into account an innovation's multiple advantages and shortcomings. Our approach incorporates-in aggregated form-patients' valuations of these advantages and shortcomings, as revealed by their actual clinical choices. Next, we outline legal changes that would harness the enormous purchasing power of public health insurance to drive a shift in medical R\&D toward investment with higher potential therapeutic payoffs. We then urge intellectual property law reforms designed to tie market exclusivity protections to clinical value. After briefly sketching an idealized value-based intellectual property regime for the health sphere, we propose adjustments to the Hatch-Waxman patent framework that governs pharmaceutical innovation to achieve much of what an ideal regime would deliver.

\section{A. Blueprint for Valuing New Clinical Methods}

A daunting difficulty besets hopes for basing medical practice on therapeutic efficacy - the elusiveness of knowledge about how well tests and treatments work. Prospective, randomized clinical trials have long been the gold standard for judging efficacy. ${ }^{292}$ But their high cost, years-long duration, and narrow patient inclusion criteria have been insurmountable obstacles to their wide use in determining clinical value, ${ }^{293}$ and feasible, science-based alternatives haven't been available.

292. Laura E. Bothwell et al., Assessing the Gold Standard-Lessons from the History of RCTs, 374 NEW ENG. J. MED. 2175, 2179 (2016).

293. Bloche, supra note 40, at 268-69. 
Over the past decade, this has changed dramatically. The "big data" and analytics revolutions have come to medicine. ${ }^{294}$ Electronic clinical records and interoperability of information systems are making it possible to compare the performance of tests and treatments in near-real time, for large numbers of patients. ${ }^{295}$ Potential confounding influences-effects on clinical results that randomization removes but that can wreak havoc on retrospective studies - can be factored out by sophisticated software as data become richer. ${ }^{296}$ Possible side effects can be tracked, as can multiple measures of clinical success. These measures of success can be combined into metrics, or ratios, of relative value for clinical interventions. These, in turn, can be multiplied by dollar amounts to generate payment rates, ${ }^{297}$ and they can power a system of value-based patenting.

Indeed, something analogous has already been achieved. Almost thirty years ago, Congress enacted 298 and Medicare implemented ${ }^{299}$ a so-called "Resource-Based Relative Value Scale"

294. Eberechukwu Onukwugha, Big Data and Its Role in Health Economics and Outcomes Research: A Collection of Perspectives on Data Sources, Measurement, and Analysis, 34 PHARMACOECONOMICs 91, 91 (2016).

295. Harlan M. Krumholz, Big Data and New Knowledge in Medicine: The Thinking, Training, and Tools Needed for a Learning Health System, 33 HEALTH AFF. 1163, 1169 (2014).

296. Medical, occupational, lifestyle, environmental-exposure, and other personal histories can be aggregated and analyzed as never before, dramatically enhancing clinical researchers' power to discern causal relationships via retrospective study. See Travis B. Murdoch \& Allan S. Detsky, The Inevitable Application of Big Data to Health Care, 309 J. AM. MED. Ass'N 1351, 1351 (2013). To be sure, these new capabilities carry privacy risks that will need to be managed effectively. See generally Nicolas P. Terry, Protecting Patient Privacy in the Age of Big Data, 81 U.M.K.C. L. REV. 385 (2012).

297. These ratios can be incorporated into the full gamut of payment methods, from fee-for-service to outlays for different "bundles" of services. So-called "bundled" payment—-designed to shift financial risk to providers and to thereby incentivize frugality-incorporates compensation for multiple clinical services into a single disbursement. Illustrations include payment to a hospital for an admission, payment to a medical practice for an episode of care (e.g., office visits, tests, and treatments for an injury), and annual, fixed, per-patient payments to a practice for all services each patient receives. These methods are grounded in projections of expense for needed services. The value-based ratios we urge can be a basis for these expense projections.

298. Omnibus Budget Reconciliation Act, H.R. 3299, 101st Cong. § 6104 (1989).

299. Medicare Program; Fee Schedule for Physicians' Services, 56 Fed. Reg. 59,624 (Nov. 25, 1991). 
(RBRVS), a set of ratios that, when multiplied by a dollar figure, yielded a fee schedule for physicians. The RBRVS was costbased-designed to take account of physicians' effort, time, and practice expenses without regard for services' therapeutic value. But it demonstrated the feasibility of basing rates on ratios meant to reflect value.

\section{Criteria for a Measure of Clinical Value}

To support a scheme of payment and patenting along the lines we urge, a measure of clinical value must meet three criteria: it should be transparent (all should be able to see how the measure treats different outcome variables), multidimensional (it should incorporate multiple things that matter, not just longevity), and dynamic (it should evolve with changes in clinical methods, evidence of efficacy, and patient preferences).

Transparency allows others to verify (or dispute) that a metric is a reasonable indicator of what it purports to measure. It thereby builds legitimacy and trust. Multidimensionality captures the reality that patients care about many treatment outcomes, including side effects, symptoms, and levels of function. These outcomes must be combined into a single metric-one that takes account of patients' preferences ${ }^{300}$ - to enable value-based payment and patenting. The import of dynamism is self-evident: technologies change, evidence of effectiveness emerges, and patients' inclinations shift.

\section{A Model from Oncology}

An instrument designed to help cancer patients make decisions about their care based on best evidence and their own preferences offers a model for the metric of clinical value we envision. Cancer treatments, like therapies for other illnesses, can be compared along different dimensions, ${ }^{301}$ including months or years

300. For example, if some patients with a particular illness are willing to sacrifice therapeutic efficacy to avert painful side effects, the metric should accommodate this preference, weighted based on the fraction of patients who hold it. More generally, valuation of tests and treatments can incorporate aggregates of these weightings, derived from patients' recorded choices. See infra text accompanying notes 301-11 (explaining the "net health benefits" strategy successfully used in oncology).

301. By contrast, it might be more difficult to measure the marginal social value of a new semiconductor material, or a new software program, since such 
of survival, time until disease progression resumes, toxicity, and measures of quality of life, ${ }^{302}$ including side effects. ${ }^{303}$ The American Society of Clinical Oncology (ASCO) recently developed a framework to help patients and physicians work through these multiple dimensions of difference.304 This framework, which yields measures of "Net Health Benefits" for therapeutic advances, collapses several dimensions onto a single axis of effectiveness.

ASCO's aim was to empower patients to make better-informed therapeutic decisions, but this instrument can be repurposed to produce the kind of value-based ratios we propose here. The instrument works by awarding (or subtracting) points for a new treatment's performance on indices of clinical benefit and toxicity. It employs a hierarchy of alternative indices of benefit, starting with a most-preferred measure, then proceeding to the next-most-favored option if good data for the higher-ranking index aren't available. Scores for each index are weighted to reflect oncologists' judgment as to how well that measure captures therapeutic effectiveness. ${ }^{305}$ "Bonus" points are then sometimes awarded when an innovation greatly outperforms standard therapy. ${ }^{306}$ The ensuing ratings are then adjusted up or down based on indices of toxicity. 307

For example, the most-preferred index for grading new therapies for "advanced" (incurable) malignancy is median time of overall survival. 308 The ASCO framework confers a categorical

items might be used in a variety of settings with heterogeneous social impacts that are difficult to compare in an apples-to-apples sense.

302. See supra Part I.A.4.

303. Beyond their unpleasantness, side effects are also a leading cause of patient non-compliance; they thus affect treatment efficacy.

304. See Lowell E. Schnipper et al., American Society of Clinical Oncology Statement: A Conceptual Framework to Assess the Value of Cancer Treatment Options, 33 J. CliniCAL ONCOLOGY 2563 (2015) [hereinafter "Schnipper et al., ASCO Framework"]; Lowell E. Schnipper et al., Updating the American Society of Clinical Oncology Value Framework: Revisions and Reflections in Response to Comments Received, 34 J. CLIN. ONCOLOGY 2925 (2016). ASCO is a professional organization of oncologists with over 40,000 members.

305. Schnipper et al., ASCO Framework, supra note 304, at 2566.

306. Id.

307. Toxicity is tallied based on severity and frequency of adverse responses to treatment. $I d$.

308. For potentially curative therapy, the most-preferred index is a hazard ratio for death-the ratio at which people receiving the new versus the standard treatment die. If this measure is unavailable, next up is median time of overall 
score (from one to five) based on a new treatment's fractional improvement in overall survival, relative to the current standardof-care. If accurate overall-survival data aren't available, the framework turns to median time of survival without disease progression (known as progression-free survival). Here, too, a categorical, one to five score is awarded, as is done (if good progression-free survival data aren't available) for the index that's next in line. But the indices are weighted differently to reflect perceived disparities in significance: the overall-survival score is multiplied by sixteen, whereas the progression-free-survival score is multiplied by eleven (the third-ranking index is multiplied by eight). 309 The resulting numbers are then adjusted up or down by up to twenty points, based on measures of toxicity. ${ }^{310}$

The ASCO framework also makes room for patients' preferences. ASCO plans to implement the framework via software that permits patients to give their own weights to different clinical outcome indicators, enabling them to strike personalized balances among measures of longevity and quality of life. These balancing decisions, we note, could be aggregated, then incorporated into valuations for new treatments, thereby taking account of patients' preferences. ${ }^{311}$

The big-data and analytics revolutions open the way for greatly-expanded use of the ASCO model. Its developers envisioned its use only with clinical trial data, but, as we will show presently, electronic medical records and machine learning make it possible to tap ongoing clinical practice to inform valuations of emerging tests and treatments. ASCO's framework is transparent, multidimensional, and dynamic-adaptable to evolving medical practice, evidence of efficacy, and patients' preferences. We spotlight it here as a demonstration-of-concept.

survival; then the framework turns to the hazard ratio for disease-free survival (the ratio at which patients in the new versus standard treatment groups survive without any evidence of cancer recurrence). $I d$.

309. Id.

310. Id.

311. There's an analogy here to economists' use of wage premiums for dangerous jobs to estimate the value of a life or life-year-these approaches incorporate preferences as revealed through market decisions. 
Others, in oncology ${ }^{312}$ and other fields, ${ }^{313}$ have constructed analogous models for assaying value. ${ }^{314}$ General consensus is emerging concerning methodology; the next step is to employ this methodology to develop a comprehensive valuation scheme for pricing and patenting purposes. ${ }^{315}$

\section{Expanding the Evidence Base: Electronic Medical Records} and Machine Learning

Constructing a comprehensive valuation scheme is only the first step; the requisite information regarding efficacy must be marshalled to support it. For reasons we've discussed, randomized clinical trials won't suffice. ${ }^{316}$ And the alternatives-retrospective and observational study of medical practice outside the clinical trial context-are fraught with selection bias and omitted-variable bias that render it difficult to rule out confounding influences on study results.

For example, suppose we want to study how cancer patients who are treated with a standard, inexpensive chemotherapy fare as compared to those who receive a new and pricey immunological treatment. It's unlikely that a given patient's therapy was randomly chosen-for instance, less well-off patients with larger

312. The National Comprehensive Cancer Network (NCCN) recently created "Evidence Blocks" that display five key features of cancer treatments: efficacy, safety, quality of evidence, consistency of evidence, and affordability. NCCN Clinical Practice Guidelines in Oncology (NCCN Guidelines ${ }^{\circledR}$ ) with NCCN Evidence Blocks ${ }^{\mathrm{TM}}$, NAT'L COMPREHENSIVE CANCER NETWORK, https://www.ncen .org/evidenceblocks/ [https://perma.cc/A7LD-KYK2]. NCCN's attention to quality and consistency of evidence is a propos when multiple studies implicate a particular treatment or regimen.

313. E.g., Jeffrey L. Anderson et al., ACC/AHA Statement on Cost/Value Methodology in Clinical Practice Guidelines and Performance Measures: A Report of the American College of Cardiology/American Heart Association Task Force on Performance Measures and Task Force on Practice Guidelines, 63 J. AM. COLL. CARDIOL. 2304 (2014) (proposing a system of value categories for cardiac care, based on QALYs added by clinical interventions).

314. Some of these models include price or cost in their assessments of value; we're not proposing to do so since we're urging a regime that would set (or negotiate) prices based on therapeutic value.

315. We plan to offer more detail about such a scheme-and to demonstrate its viability by arriving at comparative valuations of emerging cancer therapies-in future work for health-policy audiences.

316. Supra text accompanying notes $292-93$. 
copays might be more likely to receive chemotherapy, while affluent patients with better coverage might more likely choose the immunological treatment.

Given such differences, it's misleading to simply compare health outcomes for those who received chemotherapy versus the immunological treatment. The individuals in the two groups differ not only in their cancer treatment, but also in their economic and social circumstances. If the affluent are generally healthier than the less well-off for reasons having nothing to do with cancer treatment (e.g., they have healthier diets and less stressful lives), 317 then a naïve comparison of the two groups would likely overstate the relative benefit of the immunological therapy.

In statistical terms, a patient's wealth and insurance status are "omitted variables" that both affect her health and correlate with the treatment she receives. The standard approach to such confounding factors is to control for them when conducting statistical analyses. For example, in a linear regression framework, we could include a control for a patient's wealth in a regression of health on treatment options.

But what if there are other, unobservable differences between patients who receive different treatments? If we can't identify and measure these differences, we can't control for them. Large gaps and inconsistencies in collection of data that capture potentially relevant differences have historically frustrated efforts to compare tests and treatments by doing retrospective or observational studies.

Here's where electronic medical records (EMR) create transformative opportunity. EMR include data on patients at unprecedented levels of detail and consistency, ${ }^{318}$ empowering researchers to control for many differences that couldn't previously be addressed. This is bringing us closer to the comparability achievable through the classic randomized trial-and EMR datasets continue to become more comprehensive. ${ }^{319}$

317. See generally RichaRd G. WILKINSON, UNHEALthy SOCIETIES: THE AFFLICTIONS OF INEQUALITY (1996).

318. They achieve this through comprehensive, consistent information-collection templates; accumulation of data from multiple, connected health-careprovider sources; and (increasingly) interoperability of different systems.

319. Martin Cowie et al., Electronic Health Records to Facilitate Clinical Research, CLINICAL RES. CARDIOLOGY (Aug. 24, 2016), https://www.ncbi.nlm .nih.gov/pmc/articles/PMC5226988/\#Sec7title [https://perma.cc/457Z-7CYK]. 
EMR already contain rich data on millions of patients. To illustrate, current EMR oncology datasets include diagnoses, ${ }^{320}$ patient comorbidities (e.g., whether a patient has diabetes, hypertension or arthritis), complete laboratory test results, outcomes (e.g., responses to treatment, tumor progression, and sideeffects), rich demographic detail, and medical and personal history. This vast trove of data is continually being updated as medical decisions unfold and findings are recorded. Thus, we can track clinical outcomes in near-real time, for a much broader range of tests and treatments than could previously be followed.

This explosive growth in richness and accessibility of clinical data has been paralleled by a large advance in computational science-development of machine-learning algorithms ${ }^{321}$ that empower researchers to discern previously invisible patterns within data. Increasingly, these algorithms can predict a treatment's efficacy (or lack thereof) by mining EMR data for hidden patterns in patients' clinical pictures that correlate with efficacy.

Machine-learning algorithms typically solve "classification problems." A now-classic example is whether a picture includes the image of a cat. The algorithm first needs to "learn" what a cat looks like. It does so by "viewing" thousands of pictures that contain cats or non-cats and being told which pictures do and don't contain cats. After the algorithm has been "trained" on sufficient data, it is challenged to determine whether a new picture (not part of its training dataset) contains a cat.

Over the past decade, machine learning has made large strides toward solving more complex classification problems. In the last few years, dozens of reports in the medical literature have documented use of machine-learning algorithms to diagnose cancer. ${ }^{322} \mathrm{~A}$ tool developed by Google, using a recurrent neural network (a common machine-learning algorithm) has achieved $99 \%$ accuracy in identifying breast cancer on pathology

320. In the oncology context, this might include, for example: date; standardized codes for type of cancer; histology and tumor grading; tumor location and metastases; degree of extranodal, lymphovascular, and vascular invasion; Gleason grades and scores, etc.

321. The term "deep learning" is often used instead of "machine learning." The former is a subset of the latter and focuses primarily on deep neural networks, a particularly powerful machine-learning technology.

322. See Zilong Hu et al., Deep Learning for Image-Based Cancer Detection and Diagnosis-A Survey, 83 PATTERN RECOGNITION 134, 137-42 (2018). 
slides. ${ }^{323}$ Similar pattern recognition tools hold the potential to project the population-wide effectiveness of new tests and treatments by mining EMR data. These projections, in turn, can be a starting point for comparing innovations to standard care.

In short, EMR data, augmented by computational science, can approach the comparability between clinical alternatives achieved by well-designed randomized trials. This opens the way to basing prices and patent protection for medical advances on therapeutic value. An attempt at proof-of-concept for this approach is now underway. We are working with a large medical data aggregator and leaders in oncology to develop dynamic metrics of value for several therapies for colorectal and breast cancers, using actual EMR data. ${ }^{324}$

4. Leveraging Legal Presumptions to Encourage ComparativeEffectiveness Research

We recognize, nevertheless, that randomized clinical trials remain the "gold standard" for comparing the efficacy of tests and treatments. 325 They, alone, can completely eliminate confounding influences arising from unobserved differences between patients who undergo alternate diagnostic or therapeutic measures. As EMR data become more comprehensive, this concern should diminish in practice. But we can leverage this concern-and the dismay of stakeholders whose products or services disappoint in retrospective or observational studies-by treating measures of clinical efficacy based on these studies as merely creating a legal presumption concerning value.

Doctors, hospitals, or drug or device makers could then try to rebut this adverse presumption by conducting head-to-head clinical trials. Robust oversight of trial design would be essential: we'd expect some stakeholders to game the system by structuring trials so as to yield seemingly-favorable results. ${ }^{326} \mathrm{~A}$ service's or product's success in a well-designed trial would override

323. Jessica Kent, Google Deep Learning Tool 99\% Accurate at Breast Cancer Detection, HEALTH IT ANALYTICS (Oct. 22, 2018), https://healthitanalytics.com/ news/google-deep-learning-tool-99-accurate-at-breast-cancer-detection [https://perma.cc/A52R-GNZ5].

324. Our focus is on second-line use of antiangiogenic drugs (biologics) in metastatic colorectal cancer and use of everolimus in ER/PR +, HER2 negative metastatic breast cancer.

325. Supra text accompanying note 292.

326. Stakeholders could, for example, manipulate drug doses so as to make 
its poor performance in retrospective or observational studies: the metrics of efficacy we envision would prioritize clinical trial results. ${ }^{327}$ An added benefit of this presumption policy is its potential to motivate industry actors to conduct more head-to-head clinical trials, improving the evidence base for medical practice more generally.

\section{B. VAlue-Based Payment}

Neither federal nor state law can compel private health plans to pay doctors, hospitals, or drug and device makers based on therapeutic efficacy. But the sheer size of Medicare, which covers sixty million Americans, ${ }^{328}$ and Medicaid, which covers seventy-five million, ${ }^{329}$ gives these programs an outsized role in determining industry actors' revenue expectations and, thus, their R\&D decisions. The role of these programs, moreover, is likely to grow. More states are expanding Medicaid (and accepting the ACA's $90 \%$ federal subsidy), ${ }^{330}$ and the aging of the babyboom generation is powering a surge in Medicare enrollment. Moreover, there's growing political support for a quantum leap in Medicare's role: proposals receiving increased attention include making Medicare "buy-in" available via the ACA's Insurance Exchanges, lowering Medicare's age of eligibility to fifty or

competing compounds less likely to achieve therapeutic success or more likely to cause side effects. CMS, in our view, is the agency best prepared to perform the needed regulatory oversight since it has experience with assessment of comparative effectiveness for Medicare coverage purposes.

327. A variety of schemes for rating the quality of evidence have been developed by regulatory authorities and professional bodies around the world; all prioritize well-designed clinical trials over retrospective and observational studies because of the bias problems we've discussed. See generally Nat'l Acad. Press, Appendix D: Systems for Rating the Strength of Evidence and Clinical Recommendations, in CliniCAL PRACTICE GUIDELINES We CAN TRUst (2011).

328. CMS Fast Facts, CENTERS FOR MEDICARE \& MEDICAID SERVs. (July 2019), https://www.cms.gov/research-statistics-data-and-systems/statistics -trends-and-reports/cms-fast-facts/index.html [https://perma.cc/EAG6-HLQD] (discussing 2018 data).

329. Id.

330. As of February 2019, thirty-seven states (including the District of Columbia) had expanded Medicaid under the ACA to cover people with incomes up to $133 \%$ of the federal poverty line. Status of State Medicaid Expansion Decisions, KFF (Feb. 13, 2019), https://www.kff.org/medicaid/issue-brief/status-of -state-medicaid-expansion-decisions-interactive-map/ [https://perma.cc/S2PH -TXK3]. 
fifty-five, and even universal coverage via "Medicare for All." 331 And even absent such a leap, these public programs' large market share will continue to make them a model for private healthcare payers.

To harness the market power of Medicare and Medicaid, the statutory framework for these programs should be revised to require, or at least encourage, the scaling of payment for medical services and products to their clinical value. Ideally, this should be done for all that these programs cover. In practice, the psychological obstacles and institutional expectations we've discussed likely render this transformation feasible only for products and services that have not yet entered into wide clinical use.

Reimagined rate-setting along the lines we propose must start with an end to the statutory separation of price-setting and assessment of efficacy when Medicare decides whether to cover new diagnostic and therapeutic measures. ${ }^{332}$ Small gains in efficacy could suffice (as they do now) to permit coverage; to insist otherwise would be to expose the strategy we urge to ferocious, likely fatal political attack as "rationing." Pricing, though, should be tied to comparative-value metrics of the kind we describe above. ${ }^{333}$

For fee-for-service Medicare and Medicaid-and for drugs and devices-accomplishing this should be technically simple. The Social Security Act (SSA), the authorizing legislation for Medicare and Medicaid, can be amended to require creation (along the lines we've proposed) and periodic revision of comparative-value metrics for new diagnostic and therapeutic measures. Prices would then be set by multiplying the comparative-value metrics by a dollar amount. This dollar figure could be fixed initially with an eye toward keeping overall revenues from the sale of clinical services, drugs, and devices unchanged during the first few years. ${ }^{334}$ There'd be winners and losers, based on clinical success, but the industry-wide impact of this

331. Tricia Neuman et al., Medicare-for-All and Public Plan Buy-In Proposals: Overview and Key Issues, KFF (Oct. 9, 2018), https://www.kff.org/ medicare/issue-brief/medicare-for-all-and-public-plan-buy-in-proposals -overview-and-key-issues/ [https://perma.cc/7QC3-TJZX].

332. See supra text accompanying notes 156-63 (describing this separation). 333. See supra text accompanying notes 292-315.

334. This dollar figure could vary by locale to take account of regional cost differences-e.g., differences in labor and construction costs for hospitals in, say, New York City or San Francisco versus mid-sized cities and smaller towns. 
transformed pricing scheme would be roughly revenue-neutral, minimizing the political and legal resistance that business disruption invites.

For "bundled" payment ${ }^{335}$ _e.g., Medicare's disbursements to hospitals based on patients' clinical diagnoses (so-called "Diagnosis-Related Groups," or DRGs)—the comparative-value metrics we envision would need to be incorporated into the pricing of each package of services. So, for example, DRG-based payment to hospitals for assessment and treatment of pulmonary embolism (a blood clot in the lung) encompasses a basket of services (and products-e.g., drugs and devices) that CMS deems clinically appropriate. CMS combines projected costs for these services into an overall DRG "weight" (there are actually two DRGs for pulmonary embolisms with different treatment intensities). The agency then multiplies this "weight" by a "base payment rate" (which varies by hospital, depending on local labor and other costs) to generate a dollar amount to be paid to each hospital for pulmonary embolism. Now, imagine that the best available evidence shows that a new treatment significantly improves outcomes for patients with pulmonary embolism. CMS would then be required by statute to cover the new therapy, issue an initial comparative-value metric for it, then incorporate the therapy (and this metric) into its DRG "weights" for pulmonary embolism. Periodic revisions (based on tracking of clinical outcomes and patient preferences ${ }^{336}$ ) to this comparative-value metric would then trigger adjustments to DRG "weights."

When comparative-value metrics clearly show the superiority of a new clinical approach over other options, use of the new approach should become a benchmark for assessment of the quality of care provided by HMOs. Otherwise, HMOs' powerful financial incentives to stint on care (since they reduce their costs by spending less ${ }^{337}$ ) will selectively discourage them from covering those new approaches that are the most effective and thus the priciest. The quality measures that CMS uses to formulate its "star" ratings (from one to five) for Medicare HMOs should include these benchmarks, as should quality measures for Medicaid HMOs. ${ }^{338}$

335. See supra note 297.

336. See supra text accompanying notes 292-315.

337. Pegram v. Herdrich, 530 U.S. 211, 219 (2000).

338. Likewise, these benchmarks should be adopted by the ACA's "Shared 
Detailed procedures for formulating comparative-value metrics, then converting them into prices, incorporating them into "bundled" payment schemes, and translating them into quality benchmarks for HMOs are beyond our scope here. ${ }^{339}$ We underscore, though, that these administrative governance tasks aren't, in principle, more complex than implementation of Medicare's DRG and RBRVS payment schemes or pricing for Medicare HMOs. Congressional amendments to the SSA should sketch the broad outlines, leaving implementation to CMS. There will be interest group politics aplenty. But the absence of settled expectations of the sort we've discussed will reduce their ferocity and thus their potential to stymie pursuit of clinical value.

Private health plans, we note, have historically embraced Medicare payment innovations, including DRGs and the RBRVS, as models. We anticipate that private plans would likewise adopt versions of the comparative-value metrics we envision, applying them to fee negotiation, "bundled" payment, and assessment of clinical quality, hereby increasing their influence on R\&D decision-making. State regulators, ACA Health Insurance Exchanges, and accrediting bodies could also nudge private plans toward doing so-or even require it.

Tying pricing to best evidence of efficacy for new tests and treatments will incentivize innovators to incorporate high-quality comparative-effectiveness studies into the R\&D process. Today's near-total insulation of pricing from proof of efficacy discourages investment in such studies, impeding therapeutic advance and encouraging waste. ${ }^{340}$ Moreover, empowering innovators to challenge comparative value metrics assigned to new products and services by sponsoring head-to-head clinical trials, as we've proposed, ${ }^{341}$ will harness self-interest to accelerate therapeutic advance.

To accelerate transition of medical payment practice to a value-based footing, Congress could "sunset" existing, efficacy-

Savings" program for fee-for-service Medicare, which rewards groups of doctors for frugality so long as they meet the program's quality benchmarks. Patient Protection and Affordable Care Act, Pub. L. No. 111-148, § 3022, 124 Stat. 119, 137 (2010) (codified at 42 U.S.C. § 300gg-19).

339. In subsequent work for health policy audiences, we will make detailed recommendations about how this might best be done.

340. See supra text accompanying notes 117-61.

341. See supra text accompanying notes 325-27. 
disregarding payment schemes for current medical practice. A "sunset" period of seven to ten years, or even longer, followed by adoption of value-based payment along the lines we've urged for new clinical approaches, might both soften resistance to this transition for existing services and spur their stakeholders to sponsor comparative-effectiveness research. But efficacy-based payment for tests and treatments just emerging or not yet on the horizon should be a higher legislative priority. It will transform $R \& D$ incentives while engendering less political resistance; moreover, extant clinical practices tend to "sunset" on their own, through obsolescence.

\section{VAlue-Based Patents}

A value-based patent system would realign patent law with its intended goal: incentivizing socially beneficial innovation. ${ }^{342}$ Awarding a patent is, in many ways, an unnatural act-an intervention that upends an otherwise free market by bestowing a legal monopoly. Consumers pay for this monopoly through the heightened fees a patentee can charge as a monopolist. We allow patent monopolies because they are supposed to create more social value than they remove. When patent law fails to achieve its purpose, as it often does in the medical realm, its reason for being comes into question.

A value-based patent system would repair this dysfunction by making returns for medical innovation merit-based. By reshaping incentives going forward, value-based patenting would steer firms from pursuit of low-risk advances with marginal promise toward projects with greater therapeutic potential. All who invest capital or effort into potentially patentable R\&D would have enhanced motivation to press for clinical breakthroughs.

\section{A Dynamic, Value-Based Patent Term}

How might we give effect to this approach? Critical to doing so is being able to adjust the value an innovator derives from patent protection up or down, based on the innovation's social value (for health care, clinical efficacy). The most straightforward way to do this is to adjust the patent's term-the period

342. See supra text accompanying notes $283-86$. 
during which a patent owner can exclude others from using the underlying invention.

Since 1995, the baseline term for a U.S. patent has been twenty years from the date a patent application is filed. In a value-based patent system, term would depend on the clinical efficacy ${ }^{343}$ of the underlying technology. Thus, assuming the twenty-year baseline, highly effective innovations would be awarded extensions (terms longer than twenty years), while marginally beneficial technologies would receive reductions. Periodic adjustments to medical patent terms could be made as evidence of efficacy emerged-from ongoing observational and retrospective studies as well as clinical trials.

Like payment rates, variable patent terms could be based on comparative-value metrics. (These, in turn, can be derived from evidence of efficacy using models like the ASCO framework. ${ }^{344}$ ) Term extensions and reductions could be conferred along a continuum-e.g., by adding or subtracting one or more years to or from the baseline twenty. Alternatively, one could adopt a category-based approach: by analogy to ASCO's five categories of performance, ${ }^{345}$ patentable innovations could be placed into one of five (or more, or fewer) classes, based on clinical efficacy, with different patent terms. Detailed procedures for deriving patent terms from comparative-value metrics are beyond our scope here. ${ }^{346}$ This task should be simpler, though, than setting prices

343. Some might worry that our value-centric approach would give short shrift to so-called "orphan drugs," which treat rare diseases. See 21 U.S.C. § 301 (2012) (designating drugs that treat fewer than 200,000 people as orphan drugs). But we measure value at the individual patient level, not as an aggregate of total value at the population level. Hence, a drug that, on average, greatly benefits a small subset of people would be deemed highly valuable in our system. As such, highly effective orphan drugs would, in fact, receive additional patent protection under our system.

In addition, our approach would automatically address the problem of patent "evergreening," where brand-name drug makers acquire additional patents "often of doubtful validity or applicability, in order to delay generic competition." See C. Scott Hemphill \& Bhaven Sampat, Evergreening, Patent Challenges, and Effective Market Life in Pharmaceuticals, 31 J. HEALTH ECON. 327, 327 (2012). This is because such patents would be awarded minimal value if the marginal value of the innovation protected by those patents was also minimal.

344. Supra text accompanying notes 304-11.

345. See supra text accompanying notes 304-11.

346. We plan to undertake this in future work. 
for health care: Medicare's DRG and RBRVS payment schemes are far more complex. ${ }^{347}$

Importantly, a value-based patent system need not change the aggregate economic benefit that patents yield for the healthcare, drug, and device industries-in other words, the system need not be "anti-pharma" or "pro-pharma." Rather, a valuebased patent scheme can be calibrated such that the average economic value of a patent is comparable to what it is under current law.

The relative therapeutic value of tests and treatments will evolve over time as studies of efficacy unfold and new diagnostic and therapeutic alternatives emerge. ${ }^{348} \mathrm{~A}$ value-based patent system can take this into account by continually adjusting patent terms. As new drugs, devices, and other interventions enter clinical practice, near-real-time comparisons, using EMR data, open the way to dynamic patent terms-periods of market exclusivity that change in length as relative value evolves. Such a regime would perpetually offer the most protection to the highestvalue advances, encouraging firms to keep trying to "capture the flag" by pursuing clinical breakthroughs.

\section{Scientific and Competitive Uncertainty}

Some might suggest that a value-based patent system like the one sketched above would introduce harmful uncertainty into pharmaceutical and biotechnology development. This critique could take one of two forms.

First, one might claim that drug and medical device firms cannot predict at an early stage which of their prospective $R \& D$ projects will be "home runs"-technological leaps forward that decisively (and hence, cheaply ${ }^{349}$ ) treat disease. Put differently, perhaps firms just "shoot in the dark" when they pick which projects to pursue. ${ }^{350}$ If so, then a value-based system won't incentivize firms to pursue higher-value projects, simply because

347. Supra text accompanying notes 157, 299.

348. Value depends on the time and place in which a technology is utilized.

349. See supra text accompanying notes $252-73$.

350. For example, scientists might be confident that a firm is pursuing a pathbreaking new technology, only for it to fizzle in clinical trials and prove to be minimally effective or even harmful. See, e.g., Philip J. Barter et al., Effects of Torcetrapib in Patients at High Risk for Coronary Events, 357 NEW ENG. J. MED. 2109, 2109 (2007) (describing increased risk of cardiac failure and death 
there is too much scientific uncertainty as to what those projects will be.

This concern is likely overdrawn. To begin, while any one project might be risky, most companies pursue a portfolio of different projects at the same time. Risk associated with a particular project is spread across the entire portfolio. Hence, firms have reason to be more confident in the average clinical value of a full portfolio than they should be in the clinical payoff from a particular project. A value-based system would encourage firms to pursue the portfolio that has the greatest overall therapeutic potential.

In addition, firms almost certainly have some idea about the prospective value of the projects they pursue-if they didn't, they wouldn't pursue them in the first place. For example, drug companies know ex ante when they are pursuing a "me-too" product that largely replicates what another drug on the market already does. ${ }^{351}$ So they know that the marginal clinical benefit of this product will be minimal, though the potential profits may be high. Even pursuit of clinical-breakthrough possibilities is unlikely to be the product of mere guesswork. For instance, a firm's decision-makers might believe that a proposed drug targets a new molecular pathway or has some other novel mechanism of action. Attempted development of this drug will be riskier than "me-too" R\&D, but this risk hardly represents a blind leap.

Beyond invoking scientific uncertainty, critics might claim that a value-based patent system would introduce too much competitive uncertainty into technology development. A risk-averse firm might fear that its patent term for a prospective new drug will be reduced if another, better drug happens to be approved while its drug is still on-patent. This uncertainty could deter the firm from following through on the R\&D needed to bring its drug to market in the first place. It might also reduce the firm's future investment in other R\&D, since its income stream will now be at greater risk.

We partially address this concern through our proposal to phase in changes over a long-enough time to avoid impacting existing drug-development commitments. Beyond this, a dynamic patent term regime could guarantee that term extensions and

in patients who received Pfizer's torcetrapib, once thought likely to become a cardiovascular blockbuster drug).

351. See supra text accompanying notes 88-94. 
reductions will always fall within a limited range. For example, if the FDA approves a drug and the underlying patent is then extended by five years, the patentee can be given binding assurance that regardless of subsequent emergence of therapeutic alternatives, no more than a year will be added or subtracted from the patent's term. ${ }^{352}$

Even so, we recognize that any value-based patent system will yield winners and losers-that's part of the idea. But in the aggregate, value-based patenting would push pharmaceutical firms, device-makers, and other technology developers toward innovations that deliver more efficacy for money-without necessarily shrinking or growing industry's total reward.

\section{The Hatch-Waxman Framework}

The wholesale shift to value-based patenting that we've just described would require sweeping federal legislation. Existing law may offer a more pragmatic path to variable patent terms. ${ }^{353}$ The Drug Price Competition and Patent Term Restoration Act of 1984 (Hatch-Waxman Act) provides a starting point.

The Hatch-Waxman Act enables a drug patentee to extend its term for some of the delays it incurs while awaiting FDA drug approval. This extension ensures that a patentee will have some of its term left after FDA approval; otherwise, a patent could expire before the FDA concludes its review. Without FDA approval, a drug patent has no commercial value; the patent merely permits the manufacturer to bar others from making the drug. The manufacturer needs FDA approval to sell the drug to consumers.

The Hatch-Waxman Act and its patent term extension provisions are complicated, but at core, they enable a patentee to

352. Another way to address this concern would be to compare a drug or medical technology to a benchmark that precedes any technological race. For example, instead of defining the benchmark as the technology level that exists at the time a drug comes to market, the benchmark could be the technology level that existed at the time the drug developer filed its new drug application (NDA), or even the level that existed when it filed its investigational new drug (IND) application, prior to clinical trials. By defining the comparator in this way, the law could ensure that companies know the standard against which they will be measured and do not have to worry about intervening innovators whittling away their patent gains.

353. Under current law, a patent term can be adjusted for a variety of reasons. For example, a term can be increased if the U.S. Patent and Trademark Office engages in unreasonable delays while processing the application. 35 U.S.C. § 154(b) (2012). 
earn an extension of up to five years, ${ }^{354}$ with no more than fourteen years of patent life remaining after the date of FDA approval. ${ }^{355}$ This potential extension is tremendously important to pharmaceutical companies; indeed, drug patentees often make the most profit in the last years or even months of a patent's life. Each day a patent on a blockbuster drug is extended might mean millions of dollars for its owner.

We propose modifying the Hatch-Waxman framework to account for a drug's clinical efficacy. This could be done in many ways, all aimed at rewarding producers of pathbreaking rather than marginally-advantageous drugs. Most simply, Congress could direct the FDA or another agency ${ }^{356}$ to establish performance standards by regulation, based on input from leading specialist physicians vetted for conflicts of interest. These performance prerequisites should require not merely that a medication outperform the current standard of care to be eligible for a patent term extension: the drug should do uncommonly well on one or more widely-accepted performance measures or achieve an uncommonly high score on a comparative-value assessment tool like the ASCO framework.

For example, the designated agency could require that a drug for metastatic colorectal cancer increase overall survival by at least six months to be eligible for a Hatch-Waxman extension. ${ }^{357}$ Alternatively, an extension could vary continuously with

354. The extension is calculated based on two time periods: (1) a drug testing phase, which is the time between when a drug manufacturer filed an Investigational New Drug (IND) application with the FDA and when it filed a New Drug Application (NDA) after clinical trial testing; and (2) a drug approval phase, which is the time between when the manufacturer filed the NDA and when it received FDA approval. The total extension equals the sum of: half of the time in the drug testing phase (after first subtracting any time the applicant was not diligent) plus the time in the drug approval phase (again removing any time the applicant lacked diligence).

355. An example might help illustrate how this works. Consider a patent application filed in 2004, approved in 2007, and set to expire in 2024. If the underlying drug were approved by the FDA in 2021, the maximum the patent could be extended would be five years, up to 2029. If the drug were instead approved in 2012, then the patent could only be extended up to fourteen years past that date, to 2026 . So even if the patentee would otherwise be entitled to a full five-year extension, she could only receive at most a two-year extension to 2026 .

356. Among existing agencies, the principal alternatives are CMS and PCORI.

357. A more radical approach would be for the FDA to deny regulatory approval altogether for marginally-beneficial drugs. 
the therapeutic benefit provided. To illustrate, the designated agency could award an additional unit of patent term extension (say, one or a few months) for every month of additional survival by comparison with the next-best or standard alternative. Congress could also increase the maximum Hatch-Waxman extension, from five to perhaps six or seven years. ${ }^{358}$

\section{FDA-Conferred Market Exclusivity}

In addition to patent protection, conferred by the U.S. Patent and Trademark Office (PTO), the FDA has statutory authority to confer a variety of "market exclusivities"-limited shields for drug-makers against generic competition. These exclusivities (also known as "data exclusivities" or "Hatch-Waxman exclusivities") can keep generics off the market for years even absent patent protection. They, like Hatch-Waxman patent extensions, could be conditioned on showings of high relative therapeutic value, compared to next-best treatments-showings that employ the kinds of analytic and decision tools we've discussed.

The details and oft-disputed rationales for these market exclusivities are beyond our scope here. Our limited purpose in raising them is urge that they be leveraged, as law already "on the books," 359 to further incentivize R\&D that pursues therapeutic breakthroughs rather than marginally-beneficial safe bets.

358. An alternative approach would take advantage of the interaction between two FDA rules-its patent term extension rules for the "drug approval" phase (from the time a manufacturer files a New Drug Application (NDA) to when it receives FDA approval) and its rules related to priority review of NDAs. Under Hatch-Waxman, a drug patentee receives a term extension for the entire time the drug was in the "drug approval" phase (excluding time when the patentee was not diligent). See supra note 354 . The FDA also currently conducts expedited "priority review" for drugs that appear to significantly improve on current treatments in terms of safety, efficacy, diagnosis, or prevention, thereby speeding up its average review time from about ten months to six months. So if the drug approval phase time were no longer included in the patent term extension (so that the term extension depended only on the time between the IND and NDA filings), then drugs that delivered greater therapeutic value would automatically receive longer extensions, since they would receive priority review.

359. The FDA grants market exclusivities to certain approved drugs to shield them from generic competition for periods of time. An exclusivity on a drug prevents generic manufacturers from filing (and the FDA from considering) Abbreviated New Drug Applications (ANDAs) on that drug-a step essential for bringing generic competitors to market. 21 C.F.R. $§ 314.108$ (2012) (preventing filings under Federal Food Drug and Cosmetic Act $\S 505(\mathrm{j})$, which 
One might wonder why market exclusivities matter for the strategy we urge. After all, it seems likely that high marginal therapeutic benefits would trigger patent term extension, covering most or all of these exclusivity periods, enabling innovators to rely on patents to bar competitors. The answer is that branded drug manufacturers can wield market exclusivity as a legal tool for delaying would-be generic competitors from getting to market even after protective patents expire. Branded firms can invoke market exclusivity, if they have it, to keep generic rivals from asking the FDA to authorize them to bring a generic version to market. ${ }^{360}$ So preventing branded firms from obtaining market exclusivities for low- or marginal-benefit medications would enable generic competitors to get to market sooner, reducing rewards for play-it-safe $R \& D$.

\section{America's International-Trade Obligations}

The Agreement on Trade-Related Aspects of Intellectual Property Rights (TRIPS), part of the WTO (World Trade Organization) treaty system, obligates the United States and other member states to issue and enforce patents "without discrimination as to the place of invention, the field of technology and

governs ANDAs, and $\S 505(\mathrm{~b})(2)$, another path to regulatory approval of a drug that relies in part on past safety and efficacy studies). ANDAs allow generic manufacturers to piggyback on the safety and efficacy data that a branded manufacturer has provided, thereby lowering their costs and speeding up their approval time. An important market exclusivity from an economic perspective is the new-chemical-entity (NCE) exclusivity, which prohibits ANDA filings for four or five years after the FDA approves a drug if it is deemed a new entity (as opposed to an already-approved compound that is being reformulated). Another exclusivity applies to orphan drugs - those that treat conditions affecting fewer than 200,000 people: it prohibits ANDA filings for seven years after FDA approval. See 21 C.F.R. $§ 316$ (2012). A third covers pediatric medications, adding six months of exclusivity after patent expiration for drugs with approved pediatric indications. 21 U.S.C. $§ 355 a$ (2012).

360. Branded firms can do this by invoking market exclusivity to delay generic competitors from filing a so-called "Paragraph IV" certification, by which a generic firm asserts that a branded firm's patent is invalid or that the generic drug would not infringe that patent. If a generic company's Paragraph IV certification is upheld, that generic company can produce the drug, assuming the FDA approves its ANDA. See 21 U.S.C. $§ 355$ a (2012). Indeed, the FDA gives a successful Paragraph IV claimant a bounty-a 180-day market exclusivity of its own to block other generic competitors. Market exclusivity gives branded firms the ability to freeze this process. 
whether products are imported or locally produced." 361 An argument sometimes made against tailoring of patent rules to different business-sector circumstances ${ }^{362}$ is that doing so runs afoul of this non-discrimination provision.

This is unlikely to be a significant problem for our proposal. Most of the changes to patent-term extension that we've recommended operate within the Hatch-Waxman framework, which has existed since the WTO's 1994 creation without member states' having taken exception. And Hatch-Waxman is just one of many industry-specific statutes in the U.S. and Europe alone that bear on intellectual property protection. ${ }^{363}$ Neither HatchWaxman nor any other industry-specific statute has been put into doubt by a TRIPS challenge, and there's no sign of such a challenge on the horizon. 364

Intellectual property protection has also assumed a growing role in America's bilateral and regional trade agreements. A thorough review of this role is beyond our scope here, but, like TRIPS, these agreements have not endangered Hatch-Waxman

361. TRIPS: Agreement on Trade-Related Aspects of Intellectual Property Rights, art. 27, Apr. 15, 1994, Marrakesh Agreement Establishing the World Trade Organization, Annex 1C, 1869 U.N.T.S. 299 (emphasis added).

362. There have been a number of such plans. See, e.g., Michele Boldrin \& David K. Levine, The Case Against Patents, 27 J. ECON. PERSP. 3, 3 (2013) (advocating for elimination of patent protection but arguing for sector-specific terms in the alternative); Benjamin N. Roin, The Case for Tailoring Patent Awards Based on Time-to-Market, 61 UCLA L. REV. 672 (2014); Neel U. Sukhatme, Regulatory Monopoly and Differential Pricing in the Market for Patents, 71 WASH. \& LEE L. REV. 1855 (2014) (noting that differential maintenance fees across industry categories could in effect create differential patent terms across industries).

363. Other than Hatch-Waxman, these industry-specific statutes include 35 U.S.C. § 103(b) (2012) (biotechnological processes) and 17 U.S.C. §§ 901-914 (2012) (Semiconductor Chip Protection Act). Europe has also enacted a host of laws specific to biopharmaceuticals.

364. Hatch-Waxman, crafted (with bipartisan backing) as a political compromise between branded drug manufacturers and generic drug makers, retains broad support. While the Act has been criticized, a wide range of scholars and policymakers believe that, on average, it has been a success, providing a fair balance between encouraging generic drug entry (which reduces drug prices for consumers) and providing incentives for branded manufacturers to produce new compounds in the first place. See, e.g., Aaron S. Kesselheim \& Jonathan J. Darrow, Hatch-Waxman Turns 30: Do We Need a Re-Designed Approach for the Modern Era?, 15 YALE J. HEALTH POL'Y L. \& ETHICS 293, 346 (2015) (noting the Act's "generally positive record of success"). 
or any other sector-specific intellectual-property protection regimes. Soaring medical spending and proliferation of low-value tests and treatments, moreover, are global challenges, heightening prospects for transnational receptivity to new thinking about incentives for innovation in the health sphere.

\section{CONCLUSION}

Perpetually-rising health care spending is putting America's financial solvency at risk, undermining our global competitiveness, and reducing our standards of living. It's also paralyzing our politics and standing in the way of making medical care accessible to all.

Efforts over the past half century to gain control over medical spending have uniformly failed. In this Article, we've explained why-and offered a diagnosis of the problem that breaks sharply with traditional accounts of regulatory and market failure. Our explanation focuses on the psychology, economics, and social norms that drive medical innovation and lock in high-cost clinical technologies that don't deliver value. We've shown how both liberal and conservative approaches to the cost dilemma disregard these drivers out of understandable reluctance to give offense to people who are ill and afraid, to their loved ones, and to industry stakeholders. And we've urged that patients' and families' hopes and fears and stakeholders' settled expectations be acknowledged, even accepted, as inevitable features of the health policy and law landscape.

Accordingly, we've proposed an approach to America's medical-spending conundrum that aims to bend the arc of innovation. Rather than focusing on today's excessive spending, we seek to incentivize high-therapeutic-value advances and discourage emergence of low-benefit technologies. At the heart of our approach is the paradox that patients (and voters) become upset when health care payers or providers say no to marginally beneficial treatments that are available today but don't get angry about being "denied" transformative therapies that researchers will develop in the future.

To change the trajectory of technological change, we've set forth a novel, value-based approach to both pricing and patent protection that would reward innovators in proportion to the therapeutic benefits that emerging tests and treatments yield. Scaling prices and patents to therapeutic value would represent 
a sharp departure from current practice. Medicare and other public and private insurers set or negotiate prices with little regard for therapeutic impact. Health care providers and drug and medical device makers do likewise. And patent protection is generally one-size-fits-all, without legal capacity to adjust to evidence of clinical benefit.

Tying economic reward to therapeutic value would counteract the often-greater risk of failure that accompanies attempts at clinical breakthrough. We show how this can be accomplished, using cancer therapy as an example and demonstrating that assessment of clinical value can take account of multiple measures of efficacy, as well as patient preferences. Assessment of value in near-real-time, as tests and treatments emerge, has become feasible as never before, owing to the reach and power of electronic medical record data and machine learning algorithms.

We cannot predict the precise effects of our proposed healthcare payment and patent-law reforms upon medical spending's future growth. These effects will depend on legislative deals struck, regulators' refinements, patients' preferences, and health sector actors' business decisions, scientific ingenuity, and luck. But for the reasons we've set forth, we're confident that the transformation of incentives we envision will both slow clinical spending growth and dramatically enhance the therapeutic value that future spending yields. 